\title{
Del "Libre Comercio" a la quiebra del sistema colonial (1789-1796). El comercio exterior de Venezuela
}

Juan Andreo García

Universidad de Murcia

Por los estudios realizados hasta el momento, sabemos del impacto positivo de la eliminación del monopolio de la Compañáa Guipuzcoana en el comercio exterior de Venezuela; no obstante, en tales estudios se rompe la serie de valores de este comercio a partir de 1790, con lo cual, nos quedamos sin saber el impacto del decreto de Libre Comercio en la Capitanía General (28 de febrero de 1789), aunque conocemos los valores del puerto de la Guaira.

El presente trabajo establece el valor del comercio exterior de Venezuela a partir de 1791, hasta el momento en que se produce la quiebra del sistema comercial español con la crisis bélica de 1797; los datos que se aportan demuestran que es en estos años cuando el decreto de Libre Comercio para Venezuela (1789) logra sus mayores éxitos; será pues la incorporación a ese nuevo sistema comercial y no la implantación del Consulado de Caracas, la que lleve a la Intendencia de Venezuela a las más altas cotas en su comercio exterior.

Gracias a los estudios realizados sabemos del impacto positivo de la eliminación del monopolio de la Compañía Guipuzcoana en el comercio exterior de Venezuela; ahora bien, el conocimiento seriado de las cifras de ese comercio sufre un lapsus a partir de 1790; es por lo que nos quedamos sin saber qué influencia tuvo el decreto de Libre Comercio en la Capitanía General de Venezuela (28 de febrero de 1789), con la salvedad del puerto de La Guaira sobre el que sí conocemos los datos.

$\mathrm{Al}$ acceder al cargo de intendente don Esteban Fernández de León, ${ }^{1}$ el comercio venezolano se encontraba en pleno auge; hacía ya algunos años que se habían conjugado una serie de circunstancias propicias para ello: la primera fue que gracias a la labor de los intendentes Ábalos y Saavedra se había logrado desmontar la pesada maquinaria de la Compañía de Caracas (6 de mayo de 1784) que, a pesar de su discutida actividad en pro de la economía venezolana, hoy todos los estudiosos reconocen que se había convertido en una rémora para el comercio de la

I En 1791 con carácter interino. Ver Andreo García, J.: La Intendencia en Venezuela. Don Estehan Fernández de León. Intendente de Caracas. Murcia, 1991, pág. 70. 
provincia durante los últimos años de su existencia. ${ }^{2}$ Conseguido, pues, ese viejo anhelo venezolano (derribar el laberinto creado por el monopolio de la Compañía) la segunda circunstancia favorable, sería la incorporación de la Superintendencia al sistema del Libre Comercio en 1789, ya implantado hacía tiempo en otras partes del imperio. ${ }^{3}$

No obstante, hasta ese momento los avatares fueron variados y con serias dificultades para ese desarrollo comercial. Finalizada la guerra con Inglaterra, será durante los años 1779-1783, cuando el intendente Saavedra iniciará los trámites para la creación del Consulado de Caracas, ${ }^{4}$ proyecto al que se vinculan inmediatamente los comerciantes venezolanos sabedores de los beneficios que ello les reportaría, sobre todo en aquellas circunstancias en que se arrastraban aún las consecuencias de la guerra, como se aprecia en el hecho de que todavía el año 1785 fuese escaso en términos comerciales. Hasta el 25 de mayo sólo habían llegado de España dos barcos, por lo que el intendente liberaliza al comercio de algunos gravámenes; medida que genera al año siguiente una sobreabundancia de mercancías que hacen bajar estrepitosamente los precios, y es causa de que el propio intendente ordene que, en adelante, los productos importados desde España no sobrepasen el millón de pesos. ${ }^{5}$ No obstante, el profesor García-Baquero demuestra cómo la tendencia alcista del comercio de Venezuela se va a mantener, por lo menos, hasta 1790, a partir de cuya fecha ya no ha podido seriar el comercio exterior de la Capitanía. ${ }^{6}$

Estoy en disposición de poder demostrar que los años siguientes, por lo menos hasta 1796, Venezuela se mantiene en esa etapa de prosperidad comercial de la que vengo hablando y lo haré a través de los datos de las balanzas comerciales que he encontrado sobre el trienio 1791-93 (antes de la implantación del Consulado); para seguir la secuencia estadística y poder comparar aduciré datos del año más próximo, en este caso el de 1795, ya que de 1794 no he hallado dichas balanzas, aunque sí su comercio total, como después se verá. Quede bien claro que, en adelante, en los cuadros que a partir de este momento estableceré para el co-

2 Nunes Díaz, M.: El Real Consulado de Caracas, 1793-1810. Caracas, 1971, pág. 178.

3 López Cantos, Ángel: Don Francisco de Saavedra, segundo Intendente de Caracas. Sevilla, 1973, págs. 132 y 133.

4 Arcila Farías, Eduardo: El Real Consulado de Caracas. Caracas, 1957, pág. 14.

5 López Cantos, A.: Don Francisco de Saavedra..., pág. 135.

6 García Baquero-González, Antonio: "El comercio de neutrales en Venezuela, (1796-1802)". Boletín de la Academia Nacional de la Historia, tomo LXVIII, n." 271. Caracas, julio-sept. de 1985, págs, 700 y 701 . 
DEL "I.IBRE COMERCIO" A LA QUIEBRA DEL SISTEMA COLONIAL

CUAdRO N." 1

COMERCIO EXTERIOR DE VENEZUELA (1783-1790)

\begin{tabular}{ccc} 
Año & Importación & Exportación \\
\hline 1783 & 1.371 .388 & 1.234 .485 \\
1784 & 1.898 .888 & 1.443 .748 \\
1785 & 1.672 .966 & 2.191 .375 \\
1786 & 3.163 .040 & 2.275 .555 \\
1787 & 2.625 .186 & 2.123 .820 \\
1788 & 3.005 .023 & 2.151 .001 \\
1789 & 2.248 .231 & 2.572 .655 \\
1790 & 2.550 .297 & 2.129 .987
\end{tabular}

(en adelante todas las cifras serán valores en pesos fuertes y reales de vellón=p.ftes y r.v )

mercio exterior de Venezuela, no va incluido el comercio entre los puertos de la Superintendencia; datos que también poseo pero que utilizaré en trabajos posteriores.

\section{El comercio exterior durante el trienio preconsular}

\section{El año 1791}

La balanza del comercio exterior de la Intendencia de Venezuela durante este año supone el $\mathbf{9 7 , 5 \%}$ del total comerciado y resulta ser bastante equilibrada aunque ligeramente desfavorable para la Intendencia:

CUADRO N. ${ }^{\circ} 2$

BALANZA COMERCIAL DE VENEZUELA (1791)

buques valor mercancías en p.ftes.

\begin{tabular}{lll}
\hline Importación & 562 & $3.203 .209 " 4$ \\
Exportación & 513 & $3.138 .352^{\prime \prime} 7$ \\
\hline TOTAL & 1.075 & $6.341 .562 " 3$
\end{tabular}


El origen y destino de ese comercio total fue el que a continuación se manifiesta:

\section{CUADRO N." 3}

DISCRIMINACIÓN DEL COMERCIO VENEZOLANO (1791)

\begin{tabular}{|c|c|c|c|c|c|c|c|}
\hline & \multicolumn{2}{|c|}{ Importaciones } & \multicolumn{2}{|c|}{ Exportaciones } & \multicolumn{2}{|r|}{ Totales } & $\%$ \\
\hline & buques & mercancías & buques & mercancías & buques & mercancias & \\
\hline Con España & 67 & $2.171 .590 " 5$ & 53 & $2.472 .199 " 7$ & 120 & $4.643 .790 " 4$ & \\
\hline " Col. Extrj. & 36 & 76.3.307"1 & 382 & $459.441^{\prime \prime} 1 / 2$ & 74.5 & $1.222 .748^{\prime \prime} 2^{1 / 2}$ & 19 \\
\hline " resto América & 132 & $268.311 " 6$ & 78 & $206.711^{1 / 2}$ & 210 & $475.023^{\prime \prime} 4^{1 / 2}$ & \\
\hline
\end{tabular}

(Ver: Gráfico $n .{ }^{\circ}$ l)

a) Comercio con España

CUADRO N. ${ }^{\circ} 4$

COMERCIO DE LOS PUERTOS DE LA INTENDENCIA DE VENEZUELA CON ESPAÑA (1791) ${ }^{7}$

\begin{tabular}{|c|c|c|c|c|c|c|c|c|}
\hline \multirow[b]{2}{*}{ Puertos } & \multicolumn{2}{|c|}{ Importaciones } & \multicolumn{2}{|c|}{ Exportaciones } & \multicolumn{2}{|c|}{ Totales } & \multicolumn{2}{|c|}{$\%$} \\
\hline & buques & mercancias & buques & mercancías & buques & mercancias & buq. & merc: \\
\hline Guaira & 30 & 1.919 .350 & 32 & 2.215 .447 "1 & 62 & 4.134.797"1 & 52 & 89 \\
\hline Cumaná & 33 & $167.172 " 6$ & 12 & $69.222^{16} 6^{1 / 2}$ & 45 & $236.395^{1 / 2} 4^{1 / 2}$ & 37,5 & 5 \\
\hline Maracaibo & 2 & $51.586^{11} 6^{1 / 2}$ & 4 & 133.799 & 6 & $185.385 " 6^{1 / 2}$ & 5 & 4 \\
\hline Guayana & 1 & $27.356 " 4$ & 3 & $44.494 " 2^{1 / 2}$ & 4 & $71.850^{\prime \prime} 6^{1 / 2}$ & 3 & 1,5 \\
\hline Trinidad & 1 & $6.124^{11} 4^{1 / 2}$ & 2 & $9.236 " 5$ & 3 & $15.361^{1 / 2}$ & 2,5 & 0,5 \\
\hline TOTALES & 67 & $2.171 .590 " 5$ & 53 & $2.472 .199 " 7$ & 120 & $4.643 .790 " 4$ & & \\
\hline$\%$ & 56 & 46 & 44 & 54 & 100 & 100 & 100 & 100 \\
\hline
\end{tabular}

7 Archivo General de Indias. Audiencia de Caracas (en adelante AGI, Caracas), 902. Comercio de los puertos de la Capitanía General de Venezuela en 1791. 
El comercio de Venezuela con la metrópoli supone el $73 \%$ del total del comercio exterior y es, sin dudarlo, el más importante que realiza la Intendencia. Entre los puertos que lo realizan, el de La Guaira destaca abrumadoramente, pues lo hace con el $89 \%$ de las mercancías en poco más de la mitad de buques registrados. Este renglón del comercio venezolano muestra una balanza positiva para la Intendencia (en todos los puertos excepto el de Cumaná); pero me atrevo a pensar que ello es sólo una apariencia, pues es evidente que está saliendo circulante monetario que aumenta la descapitalización de la colonia, y es fácilmente comprobable que esa cantidad de dinero no retorna en frutos o productos.

Dada la importancia del comercio del puerto de La Guaira, conviene establecer su origen y destino en la metrópoli:

\section{CUADRO N. 5}

COMERCIO DE LA GUAIRA CON PUERTOS METROPOLITANOS (1791) ${ }^{8}$

\begin{tabular}{|c|c|c|c|c|c|c|}
\hline & \multicolumn{2}{|c|}{ Importaciones } & \multicolumn{2}{|c|}{ Exportaciones } & \multicolumn{2}{|c|}{ Totales } \\
\hline & buques & mercancías & buques & mercancias & buques & mercancías \\
\hline Cádiz & 12 & $1.462 .256 " 1$ & 21 & $1.813 .491 " 6^{1 / 2}$ & 33 & $3.275 .747^{1 / 2}$ \\
\hline Málaga & 9 & $314.061^{1 " 5^{1 / 2}}$ & - & - & 9 & $314.061^{1 / 5^{1 / 2}}$ \\
\hline Tenerife & 3 & $36.316^{\prime \prime} 7^{1 / 2}$ & 1 & $47.415 " 6$ & 4 & $83.732^{11} 5^{1 / 2}$ \\
\hline Santander & 5 & $75.311 " 5^{1 / 2}$ & 7 & $\left.222.692\right|^{1 / 2}$ & 11 & 298.003"7 \\
\hline Vigo & 1 & $31.403^{\prime \prime} 4^{1 / 2}$ & - & - & 1 & $31.403^{\prime \prime} 4^{1 / 2}$ \\
\hline La Coruña & - & - & 2 & $74.451^{11} 1^{1 / 2}$ & 2 & $74.451^{1 / 2}$ 1 $^{1 / 2}$ \\
\hline Pasajes & - & - & 1 & $57.397 " 1 / 2$ & 1 & $57.397^{11 / 2}$ \\
\hline
\end{tabular}

(Ver: Gráfico n. 2 )

El gráfico n. ${ }^{\circ} 2$, demuestra una vez más la importancia de los puertos andaluces $(86,5 \%)$, y dentro de esto la preponderancia, manifestada desde mucho antes, ${ }^{9}$ del eje comercial La Guaira-Cádiz; frente a los del norte de la península $(11,5 \%)$, y la existencia del nexo Venezuela-Canarias.

8 Ibídem.

9 Así lo demostraron autores como: Nunes Díaz, El Real Consulado.... Tandrón, H.: El Consulado de Caracas y el comercio exterior de Venezuela. Caracas, 1976. Álvarez, Mercedes F.: Comercio, comerciantes y sus proyecciones en la independencia venezolana. Caracas, 1963. Lucena Salmoral, M.: Vísperas de la independencia Americana: Caracas. Madrid, 1986. 
El resto de puertos de la Intendencia comerciarán con la Metrópoli, mayoritariamente vía La Guaira, de ahí una de las explicaciones del abultado comercio del puerto Caraqueño. Cumaná lo hace así sobre todo en el caso de las exportaciones; pero no en las importaciones que, en un $85 \%$, vienen directamente desde Málaga y Barcelona (con este último puerto se vincula por medio de la Compañía de Barcelona). Maracaibo y Guayana, aparte del comercio con Cádiz, tienen un cierto vínculo comercial con Santander.

\section{b) Comercio con Colonias extranjeras}

El comercio de Venezuela con las colonias extranjeras durante el año 1791 supuso el $19 \%$ del total del comercio exterior de la Intendencia; se realiza con el $69 \%$ de los buques registrados, y como se ve en la balanza final, manifiesta una clara tendencia desfavorable ya que la relación es de mayor valor de importaciones que de exportaciones.

\section{CUADRO N." 6}

COMERCIO DE LOS PUERTOS DE LA INTENDENCIA CON COLONIAS EXTRANJERAS (1791)

Importaciones $\quad$ Exportaciones $\quad$ Totales $\%$

\begin{tabular}{|c|c|c|c|c|c|c|c|c|}
\hline Puerto & buques & mercancias & buques & mercancias & buques & mercancias & buq. & merc. \\
\hline Guaira & 97 & $443.770 \mathrm{O}^{1 / 2}$ & 76 & $203.205^{1 / 2}$ & 173 & $646.975 " 5$ & 23 & 53 \\
\hline Cumaná & 141 & 130.804"5 & 170 & 133.657"5 & 311 & $246.462 " 2$ & 41 & 21,6 \\
\hline Maracaibo & 4 & $5.599 " 3$ & 4 & $764 " 7$ & 8 & $6.364 " 2$ & 1 & 0,5 \\
\hline Guayana & 66 & $81.776^{11} 3^{1 / 2}$ & 74 & $50.457 " 5$ & 140 & $132.234 " 1 / 2$ & 20 & 10,8 \\
\hline Coro & 55 & $101.356 " 4$ & 58 & $71.355 " 6$ & 113 & $172.715^{\prime \prime}$ & 15 & 14,1 \\
\hline $\begin{array}{r}\text { TOTALES } \\
\%\end{array}$ & $\begin{array}{r}363 \\
49\end{array}$ & $\begin{array}{c}763.307 " 1 \\
62.5\end{array}$ & $\begin{array}{r}382 \\
51\end{array}$ & $\begin{array}{c}459.441^{\prime \prime 1} 1^{1 / 2} \\
37.5\end{array}$ & $\begin{array}{l}743 \\
100\end{array}$ & $\begin{array}{c}1.222 .748 " 2^{1 / 2} \\
100\end{array}$ & 100 & 100 \\
\hline
\end{tabular}

Como acabo de decir, el puerto de La Guaira ocupa más de la mitad de lo comerciado; si se une su monto al del puerto de Coro resulta que la provincia de Caracas realiza el $67,1 \%$ del comercio de la Inten- 
dencia con puertos extranjeros. Le sigue en importancia el puerto de $\mathrm{Cu}$ maná, cuya balanza es ligeramente favorable a las exportaciones.

El comercio de la Intendencia de Venezuela con colonias extranjeras, en lo referente a la importación, constará sobre todo de entradas de negros bozales, oro, plata y herramientas de agricultura. Este tipo de comercio se permitirá a raíz de la Guerra de Independencia de las colonias británicas de Norteamérica y de la subsiguiente guerra con Inglaterra en 1783 y se mantendría después - sobre todo a partir del real decreto de 24 de marzo de 1789 - que vino a legalizar una situación ya existente. Según el mencionado decreto, Venezuela podía exportar sus productos - excluido el cacao- recibiendo a cambio dinero efectivo, letras de cambio, esclavos e instrumentos de agricultura; ${ }^{10}$ por otro real decreto este tipo de comercio se abrió a todos los buques españoles y extranjeros por el término de dos años, y en 1791 se prolongará por seis años más. Los puertos venezolanos abiertos a ese tráfico fueron: La Guaira, Puerto Cabello, Maracaibo, Cumaná y Barcelona. Un ejemplo de la composición de este tipo de comercio lo vemos en el siguiente cuadro:

CUADRO N. ${ }^{\circ} 7$

MERCANCÍAS IMPORTADAS POR LA GUAIRA EN 1791"1

Efectos a D. Félix Zuascavar

Herramientas de agricultura

Monedas de oro y plata

Muebles

1.777 negros bozales

Pertrechos de guerra

Víveres

Total importado

$\begin{array}{lcc}10.509 " 1 / 2 & \text { Pesos } & \text { ftes. } \\ 11.047 " 6 & " & " \\ 85.648 " 44^{1 / 2} & " & " \\ 166 & " & " \\ 328.607 & " & " \\ 2.422 " 6{ }^{1 / 2} & " & " \\ 5.333 & " & " \\ 443.770^{\prime \prime} 1^{1 / 2} & " & \end{array}$

10 Para este renglón del comercio ver: Andreo García, Juan: "La capitanía General de Venezuela y el comercio libre de negros". IX Congreso Internacional de Historia de América. AHILA. Vol. III, págs. 617 a 630. Sevilla, 1992.

11 AGI, Caracas, 902. Estado del comercio de La Guaira con los demás de América española y colonias extranjeras en el año 1791. 
Así pues, el $74 \%$ del valor total importado es en negros bozales, y el $19 \%$ es el valor de las monedas importadas. Sobran comentarios a un hecho más que normal, dados los caracteres de la economía venezolana, esclavista y deficitaria en circulante. Con referencia a las exportaciones, en la documentación consultada, no hemos podido discriminar sus valores, aunque se comprueba que las colonias extranjeras más citadas son Jamaica y Curaçao.

\section{c) Comercio con el resto de colonias españolas de América}

Supone el $8 \%$ del total del comercio exterior de la Intendencia en este año de 1791; se realiza con el 19,5\% de los buques registrados y presenta una balanza favorable a las importaciones, que suponen el $56 \%$ de lo comerciado.

\section{CUADRO N. ${ }^{\circ} 8$}

COMERCIO DE LOS PUERTOS DE LA INTENDENCIA DE VENEZUELA CON LAS COLONIAS ESPAÑOLAS EN AMÉRICA (1791) 12

$\begin{array}{lll}\text { Importaciones } & \text { Exportaciones } & \text { Totales }\end{array}$

\begin{tabular}{|c|c|c|c|c|c|c|c|c|}
\hline \multirow[b]{2}{*}{ Puertos } & \multicolumn{2}{|c|}{ Importactones } & \multicolumn{2}{|c|}{ cxportactomes } & \multicolumn{2}{|c|}{ 100iates } & \multicolumn{2}{|c|}{6} \\
\hline & buques & mercancías & buques & mercancías & buques & mercancias & buq. & merc. \\
\hline Guaira & 94 & $162.578 " 5$ & 19 & $57.584 " 6$ & 113 & $220.163 " 3$ & 56 & 47 \\
\hline Cumaná & 16 & $74.062^{\prime \prime} 2$ & 31 & $69.075 " 3$ & 47 & $143.137 " 5$ & 22,5 & 30 \\
\hline Maracaibo & 4 & $14.453 " 3$ & 8 & $72.203^{1 / 2} 1^{1 / 2}$ & 12 & $86.656 " 4^{1 / 2}$ & 5,5 & 18 \\
\hline Coro & 5 & $1.005^{\prime \prime}$ & 8 & $4.845^{\prime \prime}$ & 13 & 5.850 & 6 & 1 \\
\hline Margarita & 13 & $16.212^{\prime \prime} 4$ & 12 & $3.003 " 4$ & 25 & 19.216 & 12 & 4 \\
\hline$\%$ & $\begin{array}{r}132 \\
63\end{array}$ & $\begin{array}{c}268.311 " 6 \\
56\end{array}$ & $\begin{array}{l}78 \\
51\end{array}$ & $\begin{array}{c}206.711 " 6^{1 / 2} \\
44\end{array}$ & $\begin{array}{l}210 \\
100\end{array}$ & $\begin{array}{c}475.023 " 4^{1 / 2} \\
100\end{array}$ & 100 & 100 \\
\hline
\end{tabular}

En cuanto a los artículos comerciados, no hemos podido averiguar sus destinos y orígenes, pero sí lo suficiente para afirmar que el $66 \%$ de las importaciones del puerto de La Guaira, fueron oro y plata, y que su origen debió ser, presumiblemente, Veracruz o La Habana.

12 Ibídem. Comercio de los puertos de la Capitanía General de Venezuela en 1791. 


$$
\text { CuAdro n." } 9
$$

COMERCIO DEE LA GUAIRA CON LAS COLONIAS

FSPAÑOLAS DE AMÉRICA (1791) 13

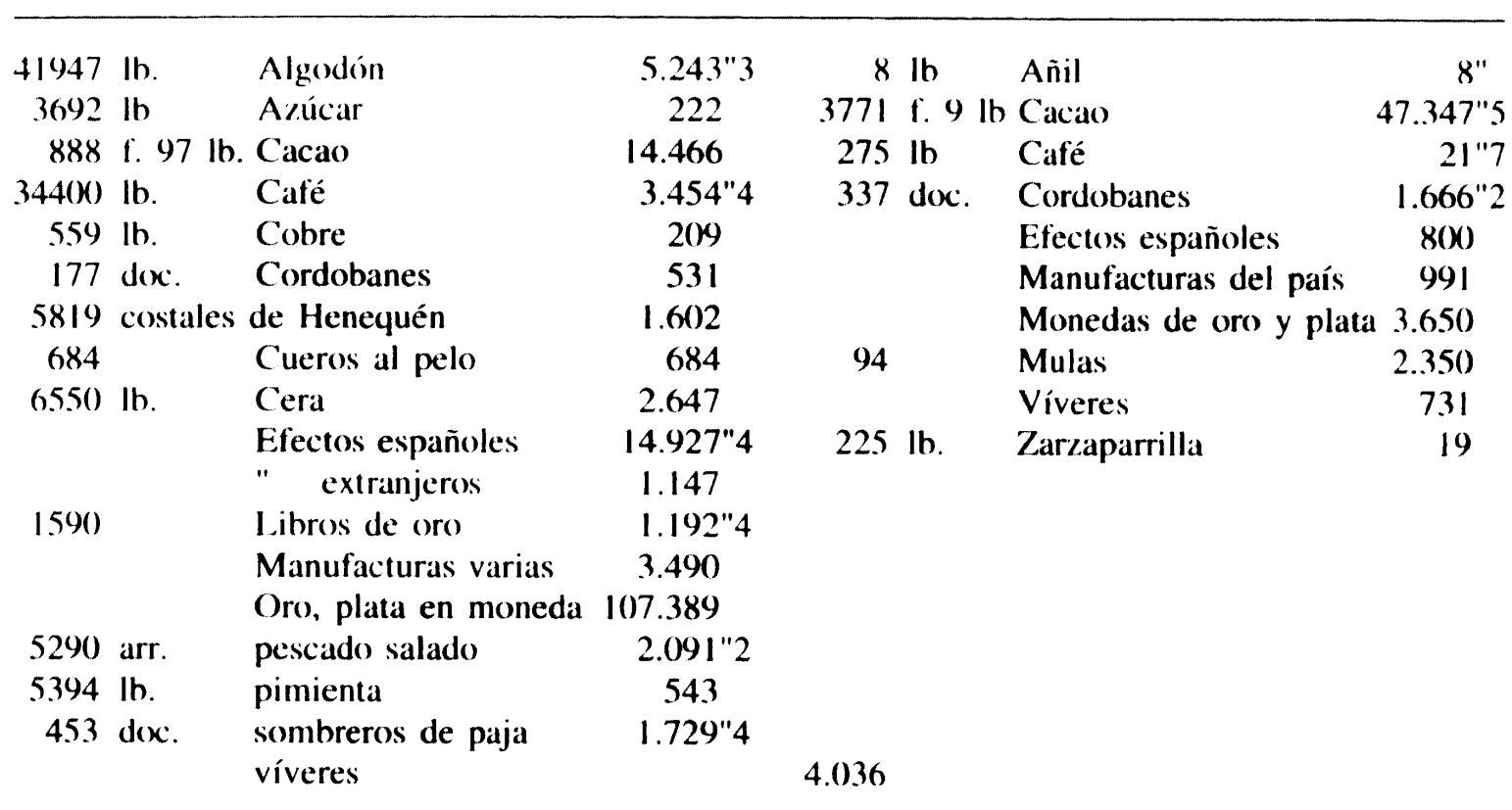

TOTAL

La diferencia entre el resto de los puertos de la Intendencia con el de La Guaira, en este tipo de comercio, no es tan acusada: de hecho $\mathrm{Cu}$ maná realiza el $30 \%$, con una balanza comercial también deficitaria; de su comercio de importación un $96 \%$ es en dinero efectivo, sobre todo con La Habana y Santo Domingo, y el de exportación el $69 \%$ con dichas plazas y el resto con Puerto Rico. Maracaibo lo hará casi en su totalidad con Veracruz, y Coro y Margarita con Cartagena, Puerto Rico y Santo Domingo.

\section{El año 1792}

La balanza del comercio exterior de la Intendencia de Venezuela durante este año supone el $92 \%$ del total comerciado y resulta ser bas-

13 Ibídem. Estado del comercio de La Guaira con América española, año 1791. 31 de diciembre de 1791. 
tante más desequilibrada que la del año anterior, con un déficit de más de dos millones a favor de las importaciones.

CUADRO N.. 10

BALANZA COMERCIAL DE VENEZUELA (1792)

buques valor mercancías en p.ftes.

\begin{tabular}{lll}
\hline Importación & 510 & $5.504 .809^{\prime \prime} 3$ \\
Exportación & 399 & $3.442 .812^{\prime \prime} 6^{1 / 2}$ \\
\hline TOTAL & 909 & $8.947 .622^{\prime \prime} 1^{1 / 2}$
\end{tabular}

La diferencia con respecto al año anterior viene marcada, precisamente, por las importaciones, ya que se ha producido una enorme avalancha de productos debido a la demanda de éstos, mientras que las exportaciones siguen su ritmo normal. El origen y destino de ese comercio fue el que a continuación se manifiesta:

\section{CUADRO N. ${ }^{\circ} 11$}

DISCRIMINACIÓN DEL COMERCIO VENEZOLANO (1792)

\begin{tabular}{lcccccccr} 
& \multicolumn{2}{c}{ Importaciones } & \multicolumn{2}{c}{ Exportaciones } & \multicolumn{2}{c}{ Totales } & $\%$ \\
& buques & mercancías & buques & mercancías & buques & mercancías & \\
\hline Con España & 154 & 4.285 .838 & 71 & $2.770 .526 " 7$ & 225 & $7.056 .364 " 7$ & 79 \\
" Col. Extrj. & 221 & $590.016^{\prime \prime}$ & 199 & $420.665 " 4$ & $1 / 2$ & 420 & $1.010 .681 " 5$ & 11 \\
" resto América & 135 & $628.955^{1 / 2} 2^{1 / 2}$ & 129 & $251.620^{\prime \prime} 3$ & 264 & $880.575 " 5$ & $1 / 2$ & 10
\end{tabular}

(Ver: Gráfico n. ${ }^{\circ}$ 3)

\section{a) Comercio con España}

Aunque sigue la misma tónica del año anterior, se aprecia mayor porcentaje de comercio exterior (79\%); la vía metropolitana parece que 
tiene menos dificultades y con menos buques (el 24,5\%), lo que indica el mayor valor de las mercancías negociadas. Como también es evidente y normal, el puerto que casi exclusivamente realiza este comercio con la metrópoli es La Guaira, con el 87,5\% del renglón. De ese comercio casi la mitad (49\%) lo hace con Cádiz a donde se envían unos 202.504 pesos fuertes en dinero efectivo. ${ }^{14}$

\section{CUADRO N.* 12}

COMERCIO DE LOS PUERTOS DE LA INTENDENCIA DE VENEZUELA CON ESPAÑA, (1792) ${ }^{15}$

\begin{tabular}{|c|c|c|c|c|c|c|c|c|}
\hline \multirow[b]{2}{*}{ Puertos } & \multicolumn{2}{|c|}{ Importaciones } & \multicolumn{2}{|c|}{ Exportaciones } & \multicolumn{2}{|r|}{ Totales } & \multicolumn{2}{|c|}{$\%$} \\
\hline & buques & mercancías & buques & mercancias & buques & mercancias & buq. & merc. \\
\hline Guaira & 57 & $3.614 .940 " 5$ & 37 & 2.553.005"2 & 94 & $6.167 .945 " 7$ & 42 & 87,5 \\
\hline Cumaná & 83 & $312.486 " 2^{1 / 2}$ & 28 & $105.218 \mathrm{"} 1 / 2$ & 111 & $417.704 " 3$ & 49,5 & 5,9 \\
\hline Maracaibo & 3 & 173.527"1 & 2 & $62.018^{1 / 2} 5^{1 / 2}$ & 5 & $235.545^{\prime \prime} 6^{1 / 2}$ & 2,2 & 3,3 \\
\hline Guayana & 5 & $162.079 " 7$ & 2 & $40.425^{\prime \prime} 5^{1 / 2}$ & 7 & $202.505^{11} 4^{1 / 2}$ & 3,1 & 2,8 \\
\hline Trinidad & 6 & $22.804 " 1 / 2$ & 2 & 9.859 "1/2 & 8 & $32.663^{\prime \prime} 1 / 2$ & 3,2 & 0,5 \\
\hline TOTALES & 154 & 4.285 .838 & 71 & $2.770 .526 " 7$ & 225 & 7.056.364"7 & & \\
\hline$\%$ & 68,5 & 60,7 & 31,5 & 39,3 & 100 & 100 & 100 & 100 \\
\hline
\end{tabular}

El resto de puertos se ocupan del $22,5 \%$ del comercio con España: Cumaná, que sigue en importancia a La Guaira, realiza casi un tercio de sus importaciones con la metrópoli vía La Guaira, lo mismo que la mayoría de sus exportaciones consignadas siempre como "a España por La Guaira", aunque también aparece comercio directo con Málaga y Barcelona. El de Maracaibo realiza su comercio directamente con Pasajes, Cádiz y Santander, aunque con un solo registro con cada uno de esos puertos. Guayana comercia casi en su totalidad directamente con Cádiz, mientras que Trinidad recibe mercancías desde Cádiz, Sevilla y Barcelona y exporta a Málaga y Cádiz.

Conviene señalar que estos datos no se parecen en nada a los que se recogen en la "Balanza de comercio de España con los Dominios de

14 Ibídem. Estado del comercio de La Guaira con España, año 1792.

15 Ibídem. Estado del comercio de la Capitanía General de Venezuela, año 1792. 
S.M. en América y en la India en 1792", ${ }^{16}$ según la cual, Venezuela exportó frutos y efectivos por valor de 62.228 .000 reales e importó por valor de 47.098.000 reales. Aparte de que las cifras no coinciden, una vez pasadas a pesos, la balanza resulta favorable para Venezuela que exporta más que importa, cuando los datos que aporto muestran todo lo contrario.

b) Comercio con colonias extranjeras

\begin{tabular}{|c|c|c|c|c|c|c|}
\hline \multicolumn{7}{|c|}{$\begin{array}{l}\text { COMERCIO DE LOS PUERTOS DE LA INTENDENCIA } \\
\text { CON COLONIAS EXTRANJERAS }(1792) 17\end{array}$} \\
\hline Importaciones & \multicolumn{2}{|c|}{ Exportaciones } & \multicolumn{2}{|r|}{ Totales } & \multicolumn{2}{|c|}{$\%$} \\
\hline jues mercancias & buques & mercancias & buques & mercancias & buq. & merc. \\
\hline $239.955 " 2$ & 65 & $126.986 " 4^{1 / 2}$ & 122 & $366.941^{\prime \prime} 7^{1 / 2}$ & 29 & 36 \\
\hline $111.792 " 7$ & 1 & $126.983^{\prime \prime} 5^{1 / 2}$ & 23 & $238.776 " 4^{1 / 2}$ & 5,4 & 23,5 \\
\hline $71.061 " 4^{1 / 2}$ & 44 & $39.909 " 2^{1 / 2}$ & 87 & $110.97(0) 7$ & 20,7 & 11 \\
\hline 26.850 & 23 & 18.404"4 & 47 & $45.254 " 4$ & 11,1 & 4,5 \\
\hline $140.359 " 3$ & 66 & $108.381 " 3$ & 141 & $284.737 " 6$ & 33,8 & 25 \\
\hline $590.016^{1 / 2}$ & 199 & $420.665^{\prime \prime} 4^{1 / 2}$ & 420 & $1.010 .681 " 5$ & & \\
\hline 58 & 47,5 & 42 & 100 & 100 & 100 & 100 \\
\hline
\end{tabular}

${ }^{*}$ Contienen datos sólo de los seis primeros meses del año.

Es de destacar, como acabo de decir, que de algunos puertos sólo conocemos datos del primer semestre y que, además, este renglón del comercio lleva incluida la negociación de negros bozales. ${ }^{18}$ Es igualmente destacable que el segundo puerto en importancia en este comercio, a pesar de poseer datos sólo del primer semestre, sea el de Trinidad de Bar-

16 Balanza del comercio de España con los dominios de S.M. en América y en la India, en el año 1792. Madrid, 1805.

17 AGI. Caracas, 902. Estado del comercio..., 1792.

18 Maracaibo importa 852 negros bozales por valor de 111.531 "7 pesos fuertes. Ibídem. Estado del comercio.... 1792. 
lovento; creo que ello es debido a que por real orden de 20) de abril de 1790) se abre la isla al Libre Comercio, como ocurrió con el resto de puertos de la Intendencia por el decreto de 24 de marzo de 1789, y además se le concede permiso para mantenerlo durante diez años. ${ }^{19}$

c) Comercio con el resto de posesiones españolas en América

$$
\text { CUADRO N.० } 14
$$

COMERCIO DE LOS PUERTOS DE LA INTENDENCIA CON COLONIAS ESPAÑOLAS EN AMÉRICA (1792) ${ }^{20}$

\begin{tabular}{|c|c|c|c|c|c|c|c|c|}
\hline \multirow[b]{2}{*}{ Puertos } & \multicolumn{2}{|c|}{ Importaciones } & \multicolumn{2}{|c|}{ Exportaciones } & \multicolumn{2}{|c|}{ Totales } & \multicolumn{2}{|c|}{$\%$} \\
\hline & buques & mercancías & buques & mercancias & buques & mercancías & buq. & merc. \\
\hline Guaira & 68 & $482.818^{\prime \prime 4}$ & 58 & 67.121 & 126 & $549.939 " 4$ & 47,4 & 64 \\
\hline Cumaná & 25 & $121.061^{1 / 2}$ & 34 & $81.166 " 6$ & 59 & $202.296 " 1 / 2$ & 22,3 & 23,5 \\
\hline Maracaibo & 5 & $4.535 " 4$ & 7 & $87.524^{11} 6^{1 / 2}$ & 12 & $92.060^{\prime \prime} 2^{1 / 2}$ & 4,5 & 10,7 \\
\hline Margarita & 14 & $\mid 0.368 " 1$ & 7 & $1.618 " 2$ & 21 & $11.986 " 3$ & 7,9 & 1,4 \\
\hline Coro & 23 & $10.103 " 7$ & 23 & $14.189^{11 / 2}$ & 46 & $24.293^{\prime \prime} 3^{1 / 2}$ & 17,6 & 0,4 \\
\hline TOTALES & 135 & $628.955^{\prime \prime} 2^{1 / 2}$ & 129 & $251.620^{\prime \prime} 3$ & 264 & $880.575^{\prime \prime} 5^{1 / 2}$ & & \\
\hline$\%$ & 51 & 73 & 49 & 27 & 100 & 100 & 100 & 100 \\
\hline
\end{tabular}

El comercio de la Intendencia con las posesiones españolas de América es claramente deficitario; más del $73 \%$ de lo comerciado es importación. Ello se debe a que más de las tres cuartas partes de lo importado es dinero efectivo (489.072 pesos) que entra por diferentes puertos, de los cuales 370.758 lo hacen por La Guaira. La provincia de Cumaná hace escaso comercio por el puerto del mismo nombre, el peso lo lleva el de Barcelona que realiza su comercio fundamentalmente con Cuba (La Habana), Santo Domingo y Puerto Rico. Maracaibo exporta más que importa, la razón es el cacao ( $99 \%$ de la exportaciones) que envía a Veracruz, desde donde importa harina y géneros de China. ${ }^{21}$ Con balanza favorable a las exportaciones aparece también Coro, que exporta a Cartagena de Indias y Cuba.

19 Ibídem. Importe del comercio realizado por la isla de Trinidad de Barlovento en 1790. Puerto España, 16 de julio de 1792.

20) Ibídem. Estado del comercio..., 1792.

21 Ibídem. Estado del comercio de Maracaibo con el resto de América, año 1792. 


\section{El año 1793}

Este año fue el primero en el que el Consulado de Caracas empezó a desarrollar su actividad; por lo que diversos autores lo han estudiado o, al menos han aportado datos sobre él. Las fuentes que he utilizado han sido fundamentalmente dos: La primera la constituyen los informes del intendente Fernández de León que engloban el comercio realizado por la provincia de Caracas, uniendo en un solo renglón los puertos de La Guaira, Coro y Puerto Cabello. ${ }^{22}$ La segunda son los estadillos de registros de entradas y salidas de cada uno de los puertos. ${ }^{23}$ Los datos que he sacado de esta segunda fuente coinciden con los aportados por el intendente con excepción de algunos casos muy concretos; posiblemente ello es debido a que, cuando se realizan los estadillos, no se incluyen algunos buques y mercancías que estaban en el puerto y aún no se habían contabilizado; algo bastante frecuente y que he podido comprobar documentalmente para el año $1795 .{ }^{24}$

Para el análisis del año, con el fin de completar al máximo la información, he utilizado ambas fuentes; con la primera se podrá contabilizar el número de buques y con la segunda, se aprecia el valor total de lo comerciado durante este año. De la interconexión entre ambas resulta el comercio exterior de la Superintendencia General de Venezuela:

\section{CUADRO N. ${ }^{\circ} 15$}

DISCRIMINACIÓN DEL COMERCIO EXTERIOR DE

LA INTENDENCIA DE VENEZUELA (1793)

Importaciones $\quad$ Exportaciones $\quad$ Totales

buques mercancías buques mercancias buques mercancias

\begin{tabular}{|c|c|c|c|c|c|c|c|}
\hline $\begin{array}{l}\text { Con España } \\
" \quad \text { Col. Extrj. } \\
" \quad \text { resto América }\end{array}$ & $\begin{array}{r}58 \\
425 \\
856\end{array}$ & $\begin{array}{l}2.003 .831 " 6 \\
1.018 .016 " 2^{1 / 2} \\
1.239 .404 " 7 \text { 1/2 }\end{array}$ & $\begin{array}{r}68 \\
482 \\
703\end{array}$ & $\begin{array}{c}2.786 .491 " 3^{1 / 2} \\
733.014 " 1 \\
418.027 " 2\end{array}$ & $\begin{array}{r}126 \\
907 \\
1559\end{array}$ & $\begin{array}{l}4.790 .323 " 1^{1 / 2} \\
1.751 .080 " 3^{1 / 2} \\
1.657 .4322^{1 / 2} 1^{1 / 2}\end{array}$ & $\begin{array}{l}58,5 \\
21,3 \\
20,2\end{array}$ \\
\hline $\begin{array}{r}\text { TOTAL } \\
\%\end{array}$ & $\begin{array}{r}1.339 \\
51,6\end{array}$ & $\begin{array}{r}4.261 .303 " \\
52\end{array}$ & $\begin{array}{r}1.253 \\
48,4\end{array}$ & $\begin{array}{c}3.937 .532 " 6^{1 / 2} \\
48\end{array}$ & $\begin{array}{r}2.592 \\
100\end{array}$ & $\begin{array}{c}8.198 .835 " 6^{1 / 2} \\
100\end{array}$ & 100 \\
\hline
\end{tabular}

22 Ibídem. Resumen del valor de géneros y frutos y efectos introducidos por los puertos del distrito de la superintendencia General subdelegada de mi cargo durante el año 1793. Firmado por Esteban Fernández de León, 7 de agosto de 1794.

23 Ibídem. Estado del comercio realizado por la Superintendencia durante el año 1793.

24 Ibídem. Informe del intendente sobre el comercio realizado en 1795. Caracas, 8 de julio de 1796. 
Ver: Gráfico n." 4

Estos datos vienen a remodelar sustancialmente ( en mas de un millón de pesos) las cifras aportadas por Baralt que la historiografía sobre el comercio venezolano venía aceptando como válidas; el mencionado autor establece para 1793 el siguiente cuadro:

CUADRO N. ${ }^{\circ} 16$

COMERCIO DE VENEZUELA EN 1793 (SEGÚN BARALT) 25

\begin{tabular}{lrrrr} 
& Importaciones & Exportaciones & Totales & $\%$ \\
\hline Con España & 2.089 .227 & 2.770 .860 & 4.860 .087 & 66.4 \\
$" \quad$ Col. Extrg. & 543.212 & 420.016 & 963.228 & 13,2 \\
resto América & 1.144 .291 & 345.254 & 1.489 .545 & 20,4 \\
\hline TOTAL & 3.776 .730 & 3.536 .130 & 7.312 .860 & 100
\end{tabular}

Se concluye, pues, que los puertos de la provincia de Caracas realizan el $70 \%$ de todo lo comerciado por la Intendencia durante ese año, con el $17 \%$ de los buques. Destaca con el $66,5 \%$ del total el puerto de La Guaira que ocupa el comercio exclusivo de toda la provincia de Caracas con la metrópoli; y cuya balanza es claramente positiva para las exportaciones en más de 200.000 pesos. En este caso, los datos sí coinciden con los aportados por Baralt, que establece para dicho puerto la siguiente balanza: importaciones: 2.583 .272 ; exportaciones: 2.735 .974 ; total: 5.319.247. ${ }^{26}$

Este puerto destina el $78,5 \%$ al comercio con España, con una balanza favorable a las exportaciones en un $60 \%$; con las posesiones españolas de América negocia el $13 \%$ y con las colonias extranjeras amigas el $7,7 \%$.

En la provincia de Caracas, sus otros puertos realizan un comercio escaso: el de Coro realiza el 1,3\% del comercio total pero sólo con la América Española y colonias extranjeras, y el de Puerto Cabello, el 2,4\% exclusivamente con colonias extranjeras.

25 Baralt: Resumen de la Historia de Venezuela de 1797 hasta 1830. Brujas-París, 1939, 2 vols., t. 1, pág. 485.

26 Ibídem, pág. 486. Apéndice n.” 2. 
Debe tenerse siempre en cuenta que he podido comprobar aproximadamente el 95\% de todo lo comerciado por la Superintendencia, según manifiesta el informe de don Esteban Fernández de León. Ateniéndonos a él, Cumaná realiza el $39 \%$ de su comercio con España, el $26 \%$ con las colonias españolas y el $35 \%$ con las extranjeras. Le sigue el puerto de Trinidad, con el $4 \%$ con España, el $26 \%$ con las colonias españolas y el $70 \%$ con las extranjeras (de estos renglones, sólo el primero es favorable a las exportaciones). El puerto de Maracaibo con el 5,3\% del comercio total de la Intendencia, realiza el $7 \%$ del mismo con España y solamente exportaciones, el $90 \%$ con las colonias españolas, sobre todo con la Nueva España (es por aquí por donde circula el cacao hacia Veracruz) y el resto, el 3\%, lo realiza con las colonias extranjeras. La Guayana realiza el $4,5 \%$ del comercio exterior venezolano, con claro predominio de las importaciones; de su total comerciado, el $46 \%$ es con la metrópoli, el $22,5 \%$ con colonias españolas y el resto, el $31,5 \%$, con las extranjeras. A Margarita corresponde el $0,3 \%$ del comercio exterior de Venezuela, no realizando comercio directo con la metrópoli, exporta a colonias extranjeras 1.320 pesos y el resto, o sea el $95 \%$ de su comercio, lo realiza con las colonias españolas en América.

Un renglón muy importante del comercio de la Superintendencia lo constituye el tráfico de negros esclavos; durante este año se introducen en Venezuela un total de 1.908 negros bozales, cuyo valor asciende a la cifra de 378.308 pesos 6 reales, y que supone el 4,6\% del total comerciado y el $8,8 \%$ de las importaciones.

\section{CUADRO N." 17}

NEGROS BOZALES INTRODUCIDOS EN EL DISTRITO DE LA SUPERINTENDENCIA (1793) ${ }^{27}$

Provincia número $\%$ valor aprox. en Ps.ftes.

$\begin{array}{lrrc}\text { Caracas } & 830 & 34,5 & 164.340 \\ \text { Cumaná } & 315 & 16,5 & 64.202 \\ \text { Trinidad } & 697 & 36,5 & 139.866 " 6 \\ \text { Guayana } & 66 & 3,5 & 9.900\end{array}$

27 AGI, Caracas, 902. Resumen del valor..., 1793. 
(1) Comercio con España

$$
\text { CUADRO N." } 18
$$

COMERCIO DE LA INTENDENCIA DE VENEZUELA CON ESPAÑA (1793)

\begin{tabular}{|c|c|c|c|c|c|c|c|c|}
\hline \multirow[b]{2}{*}{ Puertos } & \multicolumn{2}{|c|}{ Importaciones } & \multicolumn{2}{|c|}{ Exportaciones } & \multicolumn{2}{|r|}{ Totales } & \multicolumn{2}{|c|}{$\%$} \\
\hline & buques & mercancias & buques & mercancías & buques & mercancias & buq. & merc: \\
\hline Guaira & 37 & $1.680 .053^{\prime \prime 1 / 2}$ & 40 & $2.505 .372 " 2$ & 77 & $4.185 .425 " 2$ & 61 & 87,5 \\
\hline Cumaná & 15 & $222.328 " 6$ & 22 & $105.218^{1 / 2}$ & 37 & $379.735 "$ & 29,3 & 7,9 \\
\hline Maracaibo & & & 1 & $29.767 "$ & 1 & $29.767 "$ & 0,7 & 0,6 \\
\hline Guayana & 4 & $92.361 " 7$ & 4 & $78.315^{\prime \prime}$ & 8 & $170.676 " 7$ & 6,3 & 3,5 \\
\hline Trinidad & 2 & $9.0888^{1 / 2}$ & 1 & $15.631 "$ & 3 & $24.719^{\prime 1 / 2}$ & 2,3 & 0,5 \\
\hline TOTALES & 58 & $2.003 .831 " 6$ & 68 & $2.786 .49 I^{\prime \prime} 3^{1 / 2}$ & 126 & 1/2.790.323 | & & \\
\hline$\%$ & 46 & 42 & 54 & 58 & 100 & 100 & 100 & 100 \\
\hline
\end{tabular}

La Intendencia de Venezuela realiza a través de La Guaira casi la totalidad del comercio con la metrópoli. Este puerto recibe el $77 \%$ de la importaciones desde el puerto de Cádiz en 15 buques registrados (lo que indica el gran porte de éstos), el resto de importaciones provienen de Santander, Barcelona y Málaga. El puerto de La Guaira presenta una balanza favorable a las exportaciones con casi 900.000 pesos de diferencia, de las cuales el $89 \%$ se dirigen a Cádiz, destacando como renglones importantes:

Oro y plata fuerte

97.105 fanegas y 13 libras de cacao

667.905 libras de añil

209.072 libras de algodón
10.642 p.ftes.

1.586.241 p.ftes. $834.881 " 4$ p.ftes.

26.134 p.ftes. ${ }^{28}$

Para los puertos de la provincia de Cumaná su balanza comercial es favorable a las importaciones que, por orden de importancia, provienen de Barcelona, Málaga y Cádiz. Para las exportaciones no se especifica el destino, pero se puede deducir que el $89,5 \%$ de lo exportado se realiza a través del puerto de Cumaná y el resto desde Barcelona. Los buques utilizados para las importaciones son, generalmente, de gran calado; para las exportaciones, en cambio, aunque se emplean también ber-

28 Ibídem. Comercio realizado por La Guaira con los puertos de la metrópoli. La Guaira 31 de diciembre de 1793. 
gantines y goletas, la mayoría son buques pequeños como guairos y lanchas, ya que se dirigen sobre todo a La Guaira.

En importancia le sigue el puerto de la Guayana con una balanza igualmente favorable a las importaciones que provienen, en su mayoría de Cádiz y algunas de Málaga. En la misma proporción con respecto a los destinos, se reparten las exportaciones, que mayoritariamente se dirigen a Cádiz y el resto a Santander y Barcelona. ${ }^{29}$ El puerto de Maracaibo exclusivamente comercia exportando a Santander algodón, añil y azúcar. ${ }^{30}$ Por último, el puerto de Trinidad presenta - con balanza positiva para las exportaciones - un bergantín con destino a Cádiz y unas importaciones que provienen de Barcelona, Málaga y Cádiz. Estoy convencido de que el valor de la importaciones tuvo que ser mayor del que se registra, como se deduce de la nota al pie del estadillo de la balanza del puerto de Trinidad: "del valor de los efectos y géneros introducidos, se extrajo dinero para el puerto de La Guaira, cuya suma se comprende en el estado del comercio realizado por este puerto con los de América española". ${ }^{31}$

\section{b) Comercio con colonias extranjeras}

CUADRO N. ${ }^{\circ} 19$

COMERCIO DE LA INTENDENCIA DE VENEZUELA CON COLONIAS EXTRANJERAS (1793) ${ }^{32}$

Importaciones $\quad$ Exportaciones $\quad$ Totales

\begin{tabular}{lcccccccr} 
Puertos & buques & mercancias & buques & mercancias & buques & mercancias & buq. & merc. \\
\hline Guaira & 46 & $217.700^{\prime \prime} 1$ & 45 & 180.356 & 91 & $398.059^{\prime \prime}$ & 10 & 22,7 \\
Coro & 11 & $51.357^{\prime \prime} 6^{1 / 2}$ & 9 & $43.939^{\prime \prime} 1 / 2$ & 20 & $95.297^{\prime \prime}$ & 2,2 & 5,4 \\
Pto. Cabello & 40 & $117.794^{\prime \prime}$ & 39 & $81.299 "$ & 79 & $199.093^{\prime \prime}$ & 8,7 & 11,3 \\
\hline CARACAS(*) 97 & $463.048 "$ & 93 & $375.284 " 2$ & 190 & $838.332^{\prime \prime 2}$ & 20,8 & 47,8
\end{tabular}

29 Ibídem. Estado del comercio de La Guayana con la metrópoli en 1793.

30 Ibídem. Estado del comercio del puerto de Maracaibo con la metrópoli en 1793. Maracaibo, 2 de enero de 1794.

31 Ibídem. Estado del comercio realizado por el puerto de Trinidad de Barlovento con la metrópoli en 1793. Puerto España, 6 de enero de 1794.

32 Cuadro elaborado a partir de los datos extraídos de la documentación citada en notas 22 y 23. Estos cuadros presentan una novedad con respecto a los anteriores, dadas las diferentes fuentes utilizadas, he elaborado el cuadro intentando desglosar el valor de lo comerciado por cada puerto, y luego el total de lo comerciado por la provincia de Caracas, según los datos globales aportados por el intendente; ahora bien este último resultado, no tiene por que suponer la suma exacta de los anteriores. 


\section{CUADRO N. ${ }^{\circ} 19$ (continuación)}

COMERCIO DE LA INTENDENCIA DE VENEZUELA

CON COLONIAS EXTRANJERAS (1793)

\begin{tabular}{|c|c|c|c|c|c|c|c|c|}
\hline \multirow[b]{2}{*}{ Puertos } & \multicolumn{2}{|c|}{ Importaciones } & \multicolumn{2}{|c|}{ Exportaciones } & \multicolumn{2}{|c|}{ Totales } & \multicolumn{2}{|c|}{$\%$} \\
\hline & buques & mercancias & buques & mercancias & buques & mercancias & buq. & merc. \\
\hline Cumaná & 155 & $190.076 " 7^{1 / 2}$ & 225 & $150.043 " 3$ & 380 & $340.120^{\prime \prime} 2^{1 / 2}$ & 41,8 & 19,5 \\
\hline Margarita & - & - & 5 & 1.320" & 5 & $1.320^{\prime \prime}$ & 0,5 & 0,07 \\
\hline Trinidad & 110 & $280.866 " 6$ & 95 & $161.911^{1 / 2}{ }^{1 / 2}$ & 205 & $442.778^{11} 4^{1 / 2}$ & 22,8 & 25,4 \\
\hline Guayana & 61 & $76.718 " 5$ & 61 & $39.987^{\prime \prime} 4^{1 / 2}$ & 122 & $116.706^{11} 1^{1 / 2}$ & 13,5 & 6,6 \\
\hline Maracaibo & 2 & $7.356 "$ & 3 & $4.467 " 1$ & 5 & $11.823 " 1$ & 0,5 & 0,63 \\
\hline TOTALES & $\begin{array}{r}425 \\
47\end{array}$ & ${ }^{1.018 .066 " 2^{1 / 2}}$ & 482 & $733.014 " 1$ & 907 & $1.751 .080^{\prime \prime} 3^{1 / 2}$ & & \\
\hline$\%$ & 47 & 58 & 53 & 42 & 100 & 100 & 100 & 100 \\
\hline
\end{tabular}

(*) Comprende los puertos de la provincia: La Guaira, Coro y Puerto Cabello.

Como se puede apreciar, la provincia de Caracas realiza a través de sus puertos el $47,8 \%$ del este renglón del comercio, presentando una balanza favorable a las importaciones con más de la mitad del total comerciado, siendo el puerto de La Guaira el que realiza la mayor parte del mismo. Los renglones mas importantes de las importaciones de este puerto la constituyen: negros bozales (ver cuadro n. ${ }^{\circ} 17$ ) y $43.116^{\prime \prime} 1$ 1/2 pesos en oro y plata. ${ }^{33}$ En el apartado de exportaciones el $92 \%$ de las realizadas por La Guaira lo constituyen yeguas, cueros de reses y mulas. En los restantes puertos de Coro y Puerto Cabello, el renglón importado se basa casi exclusivamente en monedas de oro y plata y algunos negros bozales (ocho). ${ }^{34}$

El siguiente puerto en importancia es el de Trinidad, que presenta una balanza favorable a las importaciones. La explicación de ello aparece en nota a pie de página del estadillo: "el exceso que hay del importe de las introducciones a las extracciones, consiste en hallarse existentes todavía en la isla mucha parte de las cosechas del año próximo pasado, por haber estado en comercio intercepto por la guerra y por los negros y otras introducciones constantes pertenecientes a los colonos estableci-

33 AGI. Caracas, 902. Estado del comercio de La Guaira con colonias extranjeras en 1793. Firmado por el contador Limonta el 31 de diciembre de 1793. de 1794.

34 Ibídem. Comercio de Puerto Cabello con colonias extranjeras en 1793. 30 de junio 
dos en la agricultura"; ${ }^{35}$ consta la entrada de 697 negros bozales con un valor de 139.866"6 pesos. Las exportaciones se componen, entre otros productos de: algodón desmontado por valor de 87.626"6 pesos, azúcar por 38.164" $1 / 2$ pesos, y café por $27.591 " 5$ pesos.

Los puertos de la provincia de Cumaná siguen la misma tónica desfavorable a las exportaciones; las importaciones constan sobre todo de: monedas de plata y oro por valor de 121.167"6 pesos fuertes, 3.145 negros bozales que valen 64.202 pesos y herramientas de agricultura que incluye un alambique de 525 pesos y cuyo total ascendía a $4.707^{\prime \prime} 2^{1 / 2}$ pesos; de todo ello corresponde la mitad al puerto de Cumaná y el resto al de Barcelona. Otro tanto ocurre con las exportaciones (mulas, cueros y algodón), aunque en éstas también participa el puerto de Carúpano. ${ }^{36}$ El puerto de la Guayana participa del comercio con las potencias españolas en muy escasa medida, y ocurre lo mismo que en el de Trinidad y por las mismas causas. El renglón de las importaciones lo componen harina, monedas de oro y plata y 66 negros bozales; las exportaciones son de mulas, cueros de res y novillos. Insignificantes son las aportaciones de los puertos de Maracaibo y de Margarita. ${ }^{37}$

\section{c) Comercio con el resto de posesiones españolas en América}

\section{CUADRO N. ${ }^{\circ} 20$}

COMERCIO DE VENEZUELA CON COLONIAS ESPAÑOLAS

DE AMÉRICA (1793) ${ }^{38}$

Importaciones

Exportaciones

Totales

$\%$

Puertos Buques mercancias buques mercancías buques mercancias buq. merc.

\begin{tabular}{|c|c|c|c|c|c|c|c|c|}
\hline Guaira & 88 & $685.519^{\prime \prime} 3^{1 / 2}$ & 72 & $50.543^{\prime \prime} 1 / 2$ & 160 & 735.762" & 10,2 & 44,3 \\
\hline Coro & 8 & $5.263 " 4$ & 9 & $9.488 " 5$ & 17 & |4.752" I & 1 & 0,8 \\
\hline
\end{tabular}

$\begin{array}{llllllll}\text { CARACAS(*) } 96 & 690.789 " 4(* *) & 81 & 59.731 " 1^{1 / 2} & 177 & 750.521 " 1^{1 / 2} & 11,2 & 45,2\end{array}$

35 Ibídem. Estado del comercio realizado por Trinidad con colonias extranjeras en 1793. Puerto España, 6 de enero de 1794.

36 Ibídem. Comercio de los puertos de Cumaná con colonias extranjeras para introducir negros bozales en la provincia según real orden de 21 de septiembre de 1792.

37 Ibídem. Estado del comercio realizado por la isla Margarita con colonias extranjeras durante 1793. Puerto de Pampatar, 31 de diciembre de 1793.

38 Ibídem. Estado del comercio.... 1794. 


\author{
CUADRO N." 20 (continuación) \\ COMERCIO DE VENEZUELA CON COLONIAS ESPAÑOLAS \\ DE AMÉRICA (1793)
}

\begin{tabular}{|c|c|c|c|c|c|c|c|c|}
\hline \multirow[b]{2}{*}{ Puertos } & \multicolumn{2}{|c|}{ Importaciomes } & \multicolumn{2}{|c|}{ Exportaciones } & \multicolumn{2}{|c|}{ Totales } & \multicolumn{2}{|c|}{$\%$} \\
\hline & Buque's & mercancias & buques & mercancías & buques & mercancias & buq. & mers: \\
\hline Cumaná & 410 & $1.31 .076 "$ & 373 & $115.326 " 7$ & 783 & 246.402"7 & 50 & 14,8 \\
\hline Maracaibo & 9 & $276.382^{11 / 2}$ & 10 & $109.036^{11} 6^{1 / 2}$ & 19 & $385.419 " 6$ & 1,2 & 23,2 \\
\hline Guayana & 37 & $34.505 " 6$ & 33 & $48.88 I^{\prime \prime}$ & 70 & 83.386"6 & 4,5 & 5 \\
\hline Trinidad & 277 & $95.107 " 1$ & 120 & $72.672 " 4$ & 397 & $167.779 " 5$ & 25,5 & 10,3 \\
\hline Margarita & 27 & $11.543 " 5$ & 86 & $12.378^{\prime \prime 2}$ & 113 & $23.921 " 7$ & 7,6 & 1,5 \\
\hline TOTALES & 856 & $1.239 .404^{17} 7^{1 / 2}$ & 703 & $418.027 " 2$ & 907 & 1/657.432 & & \\
\hline$\%$ & 5.5 & 74,5 & 45 & 25,5 & 100 & 100 & 100 & 100 \\
\hline
\end{tabular}

$\left(^{*}\right)$ Corresponde a la suma de los puertos de La Guaira y Coro. $\left(^{* *}\right)$ Existe un error de $3^{\prime \prime} 3^{1 / 2}$ pesos fuertes de más entre los datos que he comprobado y el informe del Intendente Fernánde de León de fecha 7-8-1794.

La provincia de Caracas realiza su tráfico a través de dos puertos, el de La Guaira con el $44,3 \%$ del total y el de Coro con el $0,8 \%$. La diferencia entre importaciones y exportaciones es abrumadora y se debe a la gran cantidad de dinero en plata y oro que se importa, un total de 583.880 pesos con $3^{1 / 2}$ reales. El resto de la importaciones son productos varios entre los que destacan los de origen español por valor de 20.527 " 3 pesos y harina por valor de 37.590. En cuanto a las exportaciones, el $67 \%$ del total exportado es cacao por valor de $33.581 " 1$ pesos. ${ }^{39} \mathrm{El}$ puerto de Maracaibo importa un total de 276.382" $7^{1 / 2}$ pesos de los cuales 234.019"1 son en plata y oro; las exportaciones suponen algo menos de la mitad de la cifra anterior. ${ }^{40}$ De los puertos de la provincia de Cumaná, el de este nombre importa poco más de 3.600 pesos de los que 1.500 son el valor de los negros bozales introducidos, y 7.947 pesos en plata, lo que dan un valor total en importaciones de 11.550 pesos fuertes; exporta por valor de 10.960. El de Barcelona importa un total de 102.569 "7 pesos de los que 88.952 son en oro y plata; mientras que

39 Ibídem. Estado del comercio de La Guaira con América española en 1793. Firmado por el contador Limonta el 31 de diciembre de 1793.

40 Ibídem. Estado del comercio del puerto de Maracaibo con la América española, 2 de enero de 1794. 
exporta por un valor de 74.114"2 pesos. Por último el puerto de San Juan importa 7.692 pesos en plata y oro y exporta 27.404 pesos en productos varios, sobre todo reses. ${ }^{41}$ En resumen, el total de numerario en plata y oro importado por la provincia de Cumaná asciende a 112.541 pesos fuertes, además de 12 negros bozales por valor de 1.800 pesos.

En importancia de volumen comerciado, sigue el puerto de Trinidad, con importaciones por un valor de 95.107" 1 pesos fuertes, de las cuales 69.789" 1 son en monedas de plata fuerte y macuquina; la exportaciones ascienden a la suma de 72.565" 3 pesos de los cuales 10.200 corresponden a 51 negros bozales y 39.593" 3 en monedas de plata y oro, el resto son productos varios. ${ }^{42} \mathrm{El}$ puerto de la Guayana, con el de Margarita, son los únicos que en este renglón del comercio con colonias españolas presentan una balanza favorable a las exportaciones; en el primero, éstas comprenden efectos procedentes de Europa, tabaco y monedas de plata y oro por valor de $9.792 ;{ }^{43}$ las exportaciones constan de unos 12.000 pesos de productos procedentes de España y 4.604 en plata y oro. El segundo tiene una balanza favorable a las exportaciones en algo menos de mil pesos sobre las importaciones; destaca una importación de 850 pesos en plata y oro mientras que en ese mismo concepto exporta unos 3.950. ${ }^{44}$

El interés en el recuento de numerario importado durante este año, está motivado por el deseo de incidir en la endémica carencia que de éste tenía la Intendencia de Venezuela; dicho numerario asciende a una suma de unos 934.894 pesos, aproximadamente, lo que supone el $75 \%$ de todo lo importado desde el resto de colonias españolas de América. Pero aún se puede aquilatar más esa dependencia ya que para todo el año, el total de dinero que los puertos de la Superintendencia importan suma la cantidad de 1.323 .811 pesos fuertes, que suponen el $31 \%$ de todo lo importado; el origen de ese dinero es fundamentalmente de las posesiones españolas, aunque una pequeña parte procede de colonias extranjeras.

41 lbídem. Estado del comercio del puerto de Cumaná con la América española. Fechado 31 de diciembre de 1794.

42 Ibídem. Estado del comercio de la isla de Trinidad con colonias españolas. Puerto España 6 de enero de 1794.

43 Ibídem. Estado del comercio de Guayana con colonias españolas. 23 de abril de 1794.

44 Ibídem. Estado del comercio realizado por Margarita con colonias españolas. Pampatar 31 de diciembre de 1794. 


\section{Primeros años de la actuación del Consulado: 1794 y 1795}

Analizado pormenorizadamente el comercio exterior de Venezuela durante el trienio preconsular conviene, con el fin de afinar en las conclusiones, establecer los términos de una comparación; ya poseemos los datos de la época anterior que, como dijimos, se cortaba la información que se poseía en 1790; ahora creo conveniente establecer los mismos datos en la época posterior. Para ello he estudiado, en los mismos términos, los años 1794 y 1795, pues considero, con otros muchos autores, que a partir de 1796 se produce un cúmulo de circunstancias que quiebra la estructura del comercio introduciendo, a partir de ese momento, variables distintas.

Es una suerte poder contar con datos de esos años inmediatamente anteriores a la guerra con Inglaterra, lo que nos permite comparar la evolución del comercio exterior desde la etapa en que se abre el Libre comercio, los años inmediatamente anteriores a la erección del Consulado de Caracas y algunos años en que éste funciona con la tranquilidad de la paz con la Gran Bretaña; no olvido que de 1793 a 1795 España se encuentra en guerra con la Francia revolucionaria, pero como se verá, esta circunstancia no fue tan abrumadora para el comercio como la de los años siguientes.

De los años que voy a analizar a continuación hay que hacer algunas salvedades: para 1794 no he encontrado datos suficientes sobre el comercio exterior de Venezuela, sólo el total de lo comerciado; con respecto a 1795 sí he encontrado suficiente documentación y de distinta procedencia; en realidad, para este año, el problema es hacer concordar los datos y establecer, al menos aproximadamente, el cuadro del comercio tal y como hasta ahora he hecho con el trienio anterior. La documentación encontrada es la siguiente:

1.․ Informe del intendente Fernández de León, fechado en Caracas el 8 de Julio de 1796 y dirigido a D. Diego Gardoqui, ${ }^{45}$ (en adelante doc. $n .^{\circ} 1$ ); en dicho informe, se especifica que el comercio realizado por aquellas provincias durante todo el año 1794 fue de 9.856 .141 pesos 5 reales, y para 1795 la cifra de 9.941.860"6 pesos fuertes, cifra esta última que, según el intendente, no incluye el valor de la carga (1.328.141"5 pesos fuertes) de 6 buques llegados a La Guaira entre noviembre y di-

45 Ibídem. Comercio realizado por la Superintendencia de Caracas durante el año 1795. 
ciembre de ese año de 1795, procedentes de España, y que por no haberse podido descargar del todo, no se habían ajustado en aduana, no entrando pues dicho ajuste en el estado general del comercio; ${ }^{46}$ en consecuencia se puede afirmar que lo comerciado realmente durante ese año por la Intendencia de Venezuela ascendería a la cifra de $11.270 .557^{1 / 2} 5^{1 / 2}$ pesos fuertes.

2.․ En la documentación, que el mismo intendente adjunta en el citado expediente, se desprende que el total comerciado durante ese año fue lo siguiente (en adelante doc. n." 2): ${ }^{47}$

\section{CUADRO N." 21}

COMERCIO EXTERIOR DE VENEZUELA (1795).(Según doc. n. ${ }^{\circ}$ 2)

Importaciomes

Exportaciones

Totales

\begin{tabular}{cccccc} 
buques & mercancias & buques & mercancias & buques mercancias \\
\hline 1.105 & $4.335 .434^{\prime \prime} 2$ & 1.013 & $3.918 .225^{\prime \prime} 3^{1 / 2}$ & 2.118 & $8.253 .659^{\prime \prime} 5^{1 / 2}$
\end{tabular}

Es en estos datos en los que basamos la confección del cuadro de comercio realizado en 1795 . Suponen el $73 \%$ de las que habla el intendente en el documento que he señalado como n." 1 , pero son cifras comprobadas y registradas.

3. ${ }^{\circ}$. El último dato que he localizado es otro informe, ${ }^{48}$ recogido en el mismo expediente (en adelante doc. n." 3 ), en el que la Intendencia notifica que el comercio realizado durante todo el año 1795 por la provincia fue:

CUADRO N..$^{\circ} 22$

COMERCIO EXTERIOR DE VENEZUELA (1795). (Según doc. n. ${ }^{0}$ 3)

Importaciones Exportaciones Totales

$\begin{array}{lll}4.892 .739 & 4.395 .577 & 9.288 .316\end{array}$

46 Ibídem.

47 AGI, Caracas, 910. Expediente sobre el comercio de Venezuela durante el año 1795.

48 AGI, Caracas, 902. Documento citado en la nota 45. Son estos datos los que utiliza Tandrón: El consulado..., pág.70. 
Partiendo de esta diversidad de datos, pretendo establecer, lo más ajustadamente posible, cómo fue el comercio exterior de Venezuela durante 1795; insisto, aproximación en las exportaciones, ya que como he dicho, en las importaciones los datos pueden desencajarse totalmente a partir de la información dada por el documento n." 1 , sobre la no inclusión de la carga de esos 6 buques que a final de año llegan a La Guaira.

En el comercio con la metrópoli resulta que, para la exportación, según el documento n. ${ }^{\circ} 3$, la cifra gira en torno a tres millones de pesos, cifra muy aproximada a la que aporta el documento n. ${ }^{\circ} 2$, con el que he realizado el siguiente cuadro: ${ }^{49}$

\section{CUADRO N. ${ }^{\circ} 23$}

\section{COMERCIO DE VENEZUELA CON LA METRÓPOLI (1795)}

\begin{tabular}{|c|c|c|c|c|c|c|}
\hline \multirow[b]{2}{*}{ Puertos } & \multicolumn{2}{|c|}{ Importaciones } & \multicolumn{2}{|c|}{ Exportaciones } & \multicolumn{2}{|c|}{ Totales } \\
\hline & buques & mercancías & buques & mercancías & buques & mercancías \\
\hline Guaira & 36 & $2.511 .355^{\prime \prime}$ & 41 & $2.606 .054 " 6$ & 77 & $5.117 .409 " 6$ \\
\hline Cumaná & 16 & $4 \mid 4.427 " 5$ & 32 & 202.398"I & 48 & $616.825 " 6$ \\
\hline Maracaibo & 4 & $145.621 " 1$ & 3 & $53.115^{11} 1 / 2$ & 7 & $198.736^{\prime \prime} 2^{1 / 2}$ \\
\hline Guayana & 4 & $97.067^{11} 7^{1 / 2}$ & 5 & $115.449^{\prime 1} 5^{1 / 2}$ & 9 & $212.517 " 5$ \\
\hline TOTALES & 60 & $3.168 .471 " 65^{1 / 2}$ & 81 & 2.977.017"6 & 141 & $6.145 .489^{\prime \prime} 3^{1 / 2}$ \\
\hline
\end{tabular}

En ambos documentos se comprueba que a la metrópoli se envía el 89\% del total de la exportación.

Existe una diferencia mínima en las cifras relativas a los productos exportados por los puertos de la provincia de Caracas; por el documento n. 2 sabemos que por La Guaira - principal puerto de la provincia de Caracas - salen exportaciones por valor de 2.820.422" 1 pesos fuertes, según el documento n. 3 los puertos fueron: La Guaira con 2.820.422"1; Puerto Cabello con 85.512"7 y Coro con 25.955"1, lo que hace un total de $2.931 .890 " 1$ pesos fuertes y reales.

En cuanto al comercio realizado con colonias extranjeras amigas, el cuadro resultante según el documento $n .^{\circ} 2$ es el siguiente:

49 AGI, Caracas, 910. Expediente..., 1795. 


\section{CUADRO N..$^{\circ} 24$ \\ COMERCIO DE VENEZUELA CON COLONIAS EXTRANJERAS EN 1795. (Doc. n." 2)}

\begin{tabular}{|c|c|c|c|c|c|c|}
\hline \multirow[b]{2}{*}{ Puertos } & \multicolumn{2}{|c|}{ Importaciones } & \multicolumn{2}{|c|}{ Exportaciones } & \multicolumn{2}{|c|}{ Totales } \\
\hline & buques & mercancias & buques & mercancías & buques & mercancías \\
\hline $\begin{array}{l}\text { Guaira } \\
\text { Coro } \\
\text { Puerto Cabello }\end{array}$ & $\begin{array}{r}40 \\
9 \\
50\end{array}$ & $\begin{array}{l}164.450 " 2 \\
23.042 " 6 \\
101.647 " 3 \text { 1/2 }\end{array}$ & $\begin{array}{r}40 \\
9 \\
70\end{array}$ & $\begin{array}{r}191.013 " 6 \\
13.487 " 7 \\
85.362 " 7\end{array}$ & $\begin{array}{r}80 \\
18 \\
120\end{array}$ & $\begin{array}{l}355.464 " \\
36.530 " 5 \\
187.010^{\prime \prime} 2^{1 / 2}\end{array}$ \\
\hline $\begin{array}{l}\text { CARACAS(*) } \\
\text { Cumaná } \\
\text { Maracaibo } \\
\text { Guayana }\end{array}$ & $\begin{array}{r}99 \\
142 \\
3 \\
113\end{array}$ & $\begin{array}{c}289.140 " 3^{1 / 2} \\
122.302^{\prime \prime} 3^{1 / 2} \\
24.033^{\prime \prime 6} \\
171.183^{17.18}\end{array}$ & $\begin{array}{r}119 \\
135 \\
5 \\
126\end{array}$ & $\begin{array}{l}289.864 " 4 \\
106.324 " 4 \\
31.774 " 2^{1 / 2} \\
82.605 " 7\end{array}$ & $\begin{array}{r}218 \\
277 \\
8 \\
239\end{array}$ & $\begin{array}{c}579.004 " 7^{1 / 2} \\
228.407^{1 / 2} 7^{1 / 2} \\
55.808^{1 / 2} \\
253.788 " 7\end{array}$ \\
\hline TOTALES & 357 & 6)6.659"5 & 385 & $510.569^{\prime \prime} 1 / 2$ & 742 & $1.117 .228^{1 / 2}$ \\
\hline
\end{tabular}

(*) Corresponde a la suma de los puertos de La Guaira, Puerto Cabello y Coro. Las cifras llevan incorporado el valor de la negociación de negros bozales.

Las cifras, en el apartado de la importación, incorporan el valor de la negociación de negros bozales; por su importancia conviene desglosarlas:

CUADRO N. ${ }^{\circ} 25$

IMPORTACIÓN DE NEGROS BOZALES EN LA INTENDENCIA

DE VENEZUELA (1795)

Importaciones

\begin{tabular}{lccc} 
Puertos & Buques & $n^{\circ}{ }^{\circ}$ de esclavos & valor \\
\hline La Guaira & 5 & 454 & 90.800 \\
Cumaná & 59 & 322 & $62.761^{\prime \prime} 3$ \\
Maracaibo & 1 & 3 & 600 \\
Puerto Cabello & 39 & 42 & $65.004^{\prime \prime} 1 / 2$ \\
\hline Totales & 104 & 821 & $219.165^{\prime \prime} 3^{1 / 2}$
\end{tabular}

En estos datos, las exportaciones a colonias extranjeras amigas suponen el $13 \%$ de todo lo exportado por la Intendencia, para el documen- 
to n." 3 lo exportado en este renglón es el 20\%; como puede verse, las diferencias sí son aquí sustanciosas.

No ocurre lo mismo en cuanto a lo exportado a las colonias españolas de América. En este punto los dos documentos coinciden en hablar de un total del $10 \%$ de todo lo exportado. Este renglón del comercio puede desglosarse como sigue:

$$
\begin{gathered}
\text { CUADRO N. }{ }^{\circ} 26 \\
\text { COMERCIO DE VENEZUELA CON COLONIAS ESPAÑOLAS } \\
\text { DE AMÉRICA (1795) }
\end{gathered}
$$

Importaciones

\begin{tabular}{|c|c|c|c|c|c|c|}
\hline Puertos & buques & mercancías & buques & mercancías & buques & mercancias \\
\hline Guaira & 117 & 84.699" & 62 & $23.353 " 5$ & 179 & 108.052"5 \\
\hline Puerto Cabello & 3 & $1.093 " 7$ & 2 & $150^{\prime \prime}$ & 7 & $1.243 " 7$ \\
\hline Coro & 4 & 9.437" & 4 & $12.467 " 2$ & 8 & $21.904^{\prime \prime 2}$ \\
\hline $\operatorname{CARACAS}\left({ }^{*}\right)$ & 124 & $95.140^{\prime \prime} 3^{1 / 2}$ & 68 & $35.970^{\prime \prime}$ & 192 & $131.200^{\prime \prime} 6$ \\
\hline Cumaná & 191 & $150.289^{\prime \prime}$ & 291 & $143.826^{\prime \prime} 4$ & 482 & $294.115 " 4$ \\
\hline Maracaibo & 15 & $126.483^{\prime \prime} 2^{1 / 2}$ & 13 & $123.325 " 5$ & 28 & $249.807^{17} 7^{1 / 2}$ \\
\hline Guayana & 37 & 23.036"6 & 33 & $10.012^{\prime \prime} 4$ & 70 & $33.049 " 2$ \\
\hline Trinidad & 321 & 165.264 & 142 & 117.503 & 463 & 282.767 \\
\hline TOTALES & 688 & $560.302^{11 / 2}$ & 547 & $430.638 " 4$ & 1.236 & $990.941 " 3^{1 / 2}$ \\
\hline
\end{tabular}

Exportaciones

Totales

$\left(^{*}\right)$ Corresponde a la suma de los puertos de La Guaira, Puerto Cabello y Coro.

Sobre la base de estos datos y con las prevenciones de las que hemos hablado, el cuadro general por renglones de comercio a partir de la información generada por el documento n. ${ }^{\circ}$, sería el siguiente:

\begin{tabular}{|c|c|c|c|c|}
\hline & Importaciones & Exportaciones & Totales & $\%$ \\
\hline $\begin{array}{ll}\text { Con España } \\
" \quad \text { Col. Extrj. } \\
" \quad \text { resto América }\end{array}$ & $\begin{array}{l}3.168 .471^{1 / 2} 5^{1 / 2} \\
606.659 " 5^{1 / 2} \\
560.307^{1 / 2}\end{array}$ & $\begin{array}{l}2.977 .017 " 6 \\
510.569 " 1^{1 / 2} \\
430.638 " 4\end{array}$ & $\begin{array}{r}6.145 .489 " 3^{1 / 2} \\
1.117 .228 " 6^{1 / 2} \\
990.941^{1 / 3} 3^{1 / 2}\end{array}$ & $\begin{array}{l}74,46 \\
13,54 \\
12,01\end{array}$ \\
\hline TOTAL & 4.335.434"2 & $3.918 .225^{\prime \prime} 3^{1 / 2}$ & $8.253 .659^{\prime \prime} 5^{1 / 2}$ & 100 \\
\hline
\end{tabular}

$$
\text { CUADRO N. }{ }^{\circ} 27
$$

DISCRIMINACIÓN DEL COMERCIO DE VENEZUELA (1795) 
Ver: Gráfico n." 5

En consecuencia, lo que falta para hacer concordar definitivamente las fuentes que he utilizado, son las series completas de estados del comercio realizado por Venezuela con colonias extranjeras. Con esta salvedad, tomaré como datos para el total del comercio realizado en 1795 las cifras intermedias, uniendo a las importaciones el total del valor de la carga de aquellos seis buques que no se registraron, como indicaba el superintendente. El comercio total queda pues así:

CUADRO N..$^{\circ} 28$

COMERCIO EXTERIOR DE VENEZUELA (1795)

Importaciones $\quad$ Exportaciones Totales

\begin{tabular}{lrlllrl} 
Fuente & buques & mercancias & buques & mercancias & buques & mercancias \\
\hline $\begin{array}{l}\text { A.G.I. leg. 910 } \\
\text { A.G.I. leg. 902 }\end{array}$ & $\begin{array}{r}1.105 \\
6\end{array}$ & $\begin{array}{l}4.892 .739 \\
1.328 .666^{\prime \prime} 7^{1 / 2}\end{array}$ & 1.013 & 4.395 .577 & 2.118 & $\begin{array}{l}9.288 .296 \\
6\end{array}$ \\
\hline TOTAL & 1.111 & $6.221 .405^{17} 7^{1 / 2}$ & 1.013 & 4.395 .577 & 2.124 & $10.616 .982^{1 / 2} 7^{1 / 2}$
\end{tabular}

\section{Consideraciones finales}

La carencia de metales preciosos que sufre el territorio de la que será Capitanía General de Venezuela, hizo que ésta, durante los primeros siglos de colonización y conquista, quedara al margen de los circuitos comerciales generados por la metrópoli. Al variar el interés económico de la Corona española a principios del siglo XVIII, Venezuela se encontró en condiciones inmejorables para incorporarse a esa nueva circunstancia. Son múltiples los elementos que condicionan esa relativa facilidad para la incorporación de la Capitanía a los circuitos comerciales que empiezan a abrirse:

a) Su suelo y su clima producen una enorme variedad de frutos tropicales.

b) Es la parte del imperio español más cercana a las costas metropolitanas.

c) Posee una enorme extensión de costa con variedad de puertos naturales. 
d) Su ubicación en el Caribe permite la fácil navegación entre su costa y los enclaves europeos de las Antillas.

Si para todas las colonias españolas, por su esencial dependencia respecto de España, el comercio va a ser algo trascendental, para Venezuela va a ser algo vital, supone el "oxígeno" que permite la vida a la colonia; a través de él, además de dar salida a productos locales y la entrada a los europeos, circula la tan necesaria "plata", que permitió el sustento de la economía venezolana, secularmente tan escasa de numerario circulante. Desde la implantación de la Compañía Guipuzcoana, el comercio se convierte en el don más preciado de las provincias venezolanas; esta es la razón por la que muchas de la Reformas Borbónicas implantadas allí, intentarán, por todos los medios, relanzarlo y protegerlo; esa al menos es la intención de la Intendencia y del Consulado. ${ }^{50} \mathrm{Pe}$ ro al mismo tiempo, ocurrirá en esa parte del imperio lo que en el resto; cualquier circunstancia externa que provoque dificultades en la actividad comercial, generará indefectiblemente una crisis económica que, en el caso de Venezuela, por todo lo que vengo exponiendo, adquirirá una virulencia especial a finales del siglo XVIII. Las sucesivas guerras, primero con la Gran Bretaña (1779-1783), después con Francia (1793-1796) y de nuevo con la Gran Bretaña (1797-1802), incidirán de forma muy directa en la sensible economía, y en consecuencia, en la situación social y política de la Capitanía General de Venezuela.

Venezuela se incorpora al sistema de Libre Comercio por la real orden de 28 de febrero de 1789; ahora bien, se puede afirmar que "de facto" lo hará a partir del momento en que desaparece el monopolio de la Compañía Guipuzcoana de Caracas (1781); no obstante, como el profesor García-Baquero afirma, ${ }^{51}$ además de que no se poseen datos hasta 1783, Venezuela, como el resto del imperio, estaba sufriendo en estos momentos la interrupción del tráfico con la metrópoli por razón de la guerra con Inglaterra (1779-1783); por lo que para un análisis de la incidencia del Libre Comercio en la provincia de Venezuela, conviene adelantarse a la fecha de 1783 que es, como dije, el momento en que se incorpora la mencionada provincia al nuevo sistema comercial.

No cabe duda de que sería interesantísimo poder establecer las pautas diferenciales del comportamiento comercial de Venezuela, en relación

50 Nunes Díaz, Manuel: El Real Consulado..., pag, 119. Morazzani de Pérez Enciso, Gisela: La Intendencia en España y América. Caracas, 1966, págs. 157 y ss.

51 García-Baquero González, A: "El comercio de neutrales...", pág. 675. 
con el resto de América, partiendo de la fecha de implantación del reglamento de Libre Comercio (1778); pero eso no es posible, pues no existen estudios generales que recojan el comportamiento comercial en todos los renglones de comercio exterior (comercio con la metrópoli, con las colonias españolas y con las extranjeras), de todas y cada una de las partes del imperio; y aunque sí se conocen datos del comercio de América con España, ${ }^{52}$ ello serviría a mi propósito sólo de forma sectorial, para el análisis del comercio de Venezuela con la Península.

Lo que sí estoy en disposición de hacer, tras la consulta de los datos que ya se conocían y los que acabo de aportar, es establecer la secuencia total del comercio exterior de Venezuela a partir de 1783 hasta la implantación del Consulado (1793) y, aún más, comprobar el impacto de la puesta en marcha de esa institución, al menos hasta que se inicia el otro gran colapso mercantil que supuso la guerra con Inglaterra (1797-1802). A partir de ese momento desconocemos, como dije, la continuación de la secuencia estadística de la Superintendencia, aunque sí se conoce la del puerto más importante, La Guaira.

Así pues, la serie del comercio exterior de la Intendencia de Venezuela, queda como a continuación se especifica.

52 García-Baquero González, A.: Comencio colonial y guerras revolucionarias. Sevilla, 1972. Mas recientemente, Fisher, J.: Relaciones económicas entre España y América hasta le Independencia. Madrid, 1992. Este autor establece el crecimiento de los diferentes renglones del comercio con América, partiendo del año 1778 como base 100 (págs. 177 y 196):

Exportaciones España América

Importaciones España América

\begin{tabular}{ccccc} 
año & total mercancias & crecimiento\% & Total mercancias & crecimiento.\% \\
\hline 1778 & 74,5 & 100 & 76,4 & 100 \\
1782 & 112,7 & 151 & 110,8 & 149 \\
1783 & 136,8 & 184 & 171,5 & 230 \\
1784 & 435,6 & 585 & 551,0 & 739 \\
1785 & 457,7 & 614 & $1.150,0$ & 1542 \\
1786 & 339,3 & 455 & 810,8 & 1087 \\
1787 & 258,7 & 347 & 609,1 & 817 \\
1788 & 305,2 & 410 & 947,8 & 1271 \\
1789 & 326,5 & 438 & 993,0 & 1332 \\
1790 & 292,2 & 392 & 941,7 & 1263 \\
1791 & 370,3 & 497 & $1.203,7$ & 1617 \\
1792 & 441,5 & 593 & 933,8 & 1253 \\
1793 & 307,3 & 412 & 888,6 & 1192 \\
1794 & 185,8 & 249 & $1.061,6$ & 1424 \\
1795 & 282,1 & 379 & 905,4 & 1214 \\
1796 & 251,9 & 338 & $1.149,2$ & 1541
\end{tabular}

(En millones de reales de vellón) 
CUADRO N.० 29

COMERCIO EXTERIOR DE VENEZUELA, 1783-1795

\begin{tabular}{|c|c|c|c|c|c|c|c|}
\hline \multirow[b]{2}{*}{ años } & \multicolumn{2}{|c|}{ Importaciones } & \multicolumn{2}{|c|}{ Exportaciones } & \multicolumn{2}{|r|}{ Totales } & \multirow[b]{2}{*}{ incremento\% } \\
\hline & buques & mercancias & buques & mercancias & buques & mercancias & \\
\hline 1783 & & 1.371 .388 & & 1.234 .495 & & 2.605 .883 & 100 \\
\hline 1784 & & 1.898 .888 & & 1.443 .748 & & 3.342 .636 & 128 \\
\hline 1785 & & 1.671 .966 & & 2.191 .375 & & 3.863 .341 & 148 \\
\hline 1786 & & 3.163 .040 & & 2.275 .555 & & 5.438 .603 & 208 \\
\hline 1787 & & 2.625 .186 & & 2.123 .820 & & 4.749 .006 & 182 \\
\hline 1788 & & 3.005 .023 & & 2.151 .001 & & 5.156 .024 & 197 \\
\hline 1789 & & 2.248 .231 & & 2.572 .655 & & 4.820 .886 & 185 \\
\hline 1790 & & 2.550.297 & & 2.129 .987 & & 4.680 .284 & 179 \\
\hline 1791 & 740 & $3.291 .250^{\prime \prime} 7^{1 / 4}$ & 906 & $3.208 .877 " 6$ & 1645 & $6.500 .128^{\prime \prime} 5^{1 / 4}$ & 249 \\
\hline 1792 & 1047 & $5.781 .575^{1 / 2}$ & 1174 & $3.935 .015^{1 / 2} 7^{1 / 2}$ & 22221 & $9.716 .591 " 5$ & 372 \\
\hline 1793 & 1339 & 4.261 .303 & 1253 & $3.937 .532^{11} 6^{1 / 2}$ & 22592 & $8.198 .835 " 6$ & 314 \\
\hline 1794 & & & & & & 9.856.141"5 & 378 \\
\hline 1795 & 1111 & $6.221 .405^{11} 7^{1 / 2}$ & 1013 & 4.395.577 & 2.124 & $10.616 .982^{11 / 2}$ & 407 \\
\hline
\end{tabular}

Ver: Gráfico n. ${ }^{\circ} 6$

Es fácil comprobar que las balanzas comerciales de Venezuela durante el período estudiado son casi siempre desfavorables a la Intendencia (se importa más que se exporta), exceptuando dos momentos: los años 1785 y 1789; el primero porque termina la guerra con Francia, y aún se arrastran las consecuencias de ella en el nexo de unión atlántico, y sobre todo porque pueden salir algunos stocks de existencias desde Venezuela; a partir de ese momento las medidas liberalizadoras del intendente hacen que la demanda se dispare y aumente la importación, lo que, como dije, produce una sobreabundancia de productos que hicieron bajar los precios; por ello se aprestan medidas correctoras para hacer bajar las cantidades de productos llegados desde la metrópoli, y se produce una suave bajada de importaciones hasta 1789. En segundo lugar porque es en esta última fecha, cuando Venezuela se incorpora - de facto- al sistema de Libre Comercio. En cuanto a las exportaciones, mantienen un crecimiento sostenido, hasta el fin de la coyuntura bélica con Francia, conservándose después en unos valores constantes hasta 1791 en que el aumento es de más de un millón de pesos con respecto al año anterior.

En consecuencia la incorporación de Venezuela al Libre Comercio supone un impacto verdaderamente espectacular en su actividad comer- 
cial; de manera que la implantación del Real Consulado de Caracas, no tiene especial relevancia en cuanto a los resultados del comercio exterior, aunque opino que no será lo mismo en lo tocante a los otros fines de la institución. Estoy convencido de que la verdadera incidencia, en cuanto al comercio exterior, se verá a partir de 1797, inicio de la gran crisis del comercio atlántico y de la incorporación de Venezuela al comercio con neutrales.

Llama la atención el pico de sierra que se produce en las importaciones durante 1792. Es el intendente, como señalé, el que explica el hecho: que frente al peligro inminente de nueva guerra con la Francia revolucionaria, Venezuela hace acopio de productos de importación. Con todo, esta nueva coyuntura bélica, por la propia situación del enemigo y sobre todo por la nueva situación surgida a partir del decreto de 1789, no tendrá apenas incidencia en la Intendencia, que se mantendrá en un progresivo crecimiento en su comercio.

$\mathrm{Si}$ se ven las cifras globales del comercio exterior, se aprecia cómo al final de la coyuntura estudiada, el crecimiento es de un $407 \%$ con respecto a la fecha de 1783 , produciéndose el verdadero despegue a partir de 1789, o mejor a partir de 1790; son pues los años que acabo de estudiar cruciales para comprobar en su verdadera dimensión las consecuencias de la liberalización del comercio en la Superintendencia de Venezuela.

Ver: Gráfico n. ${ }^{\circ} 7$ 


\section{Civitiveos}

Linien:

and and
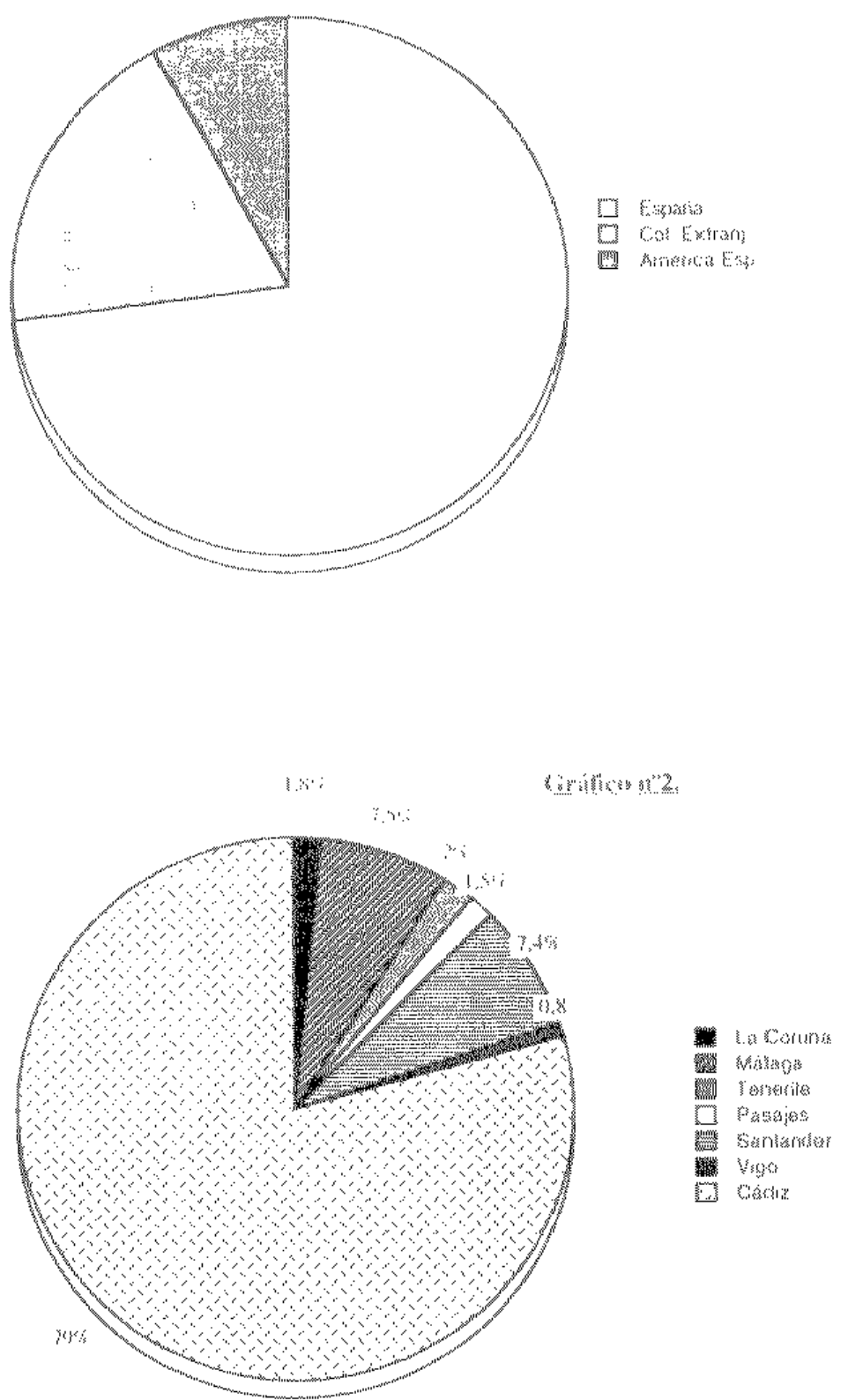

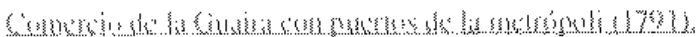


Ginkming

mom mond

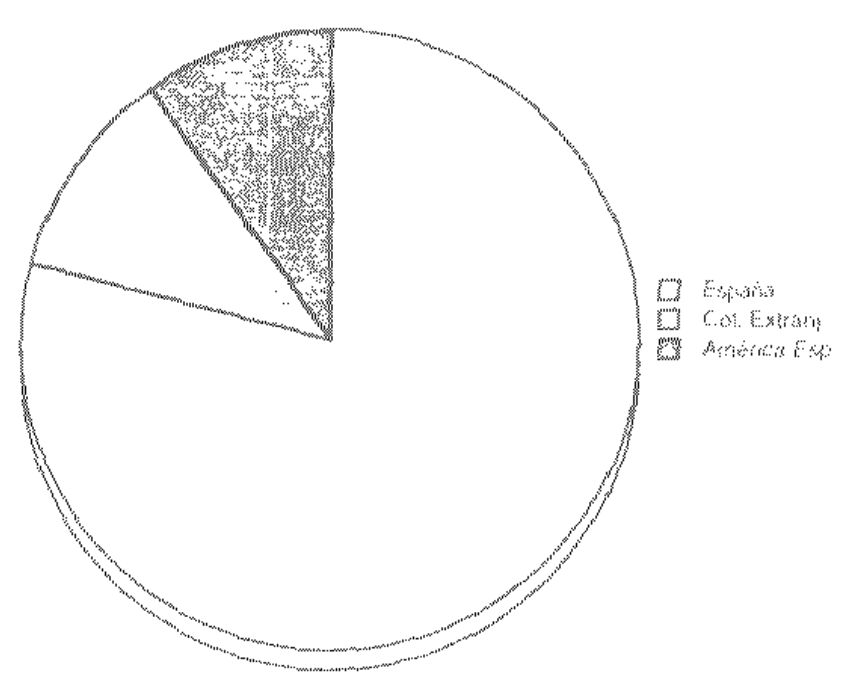

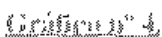

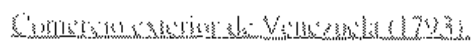

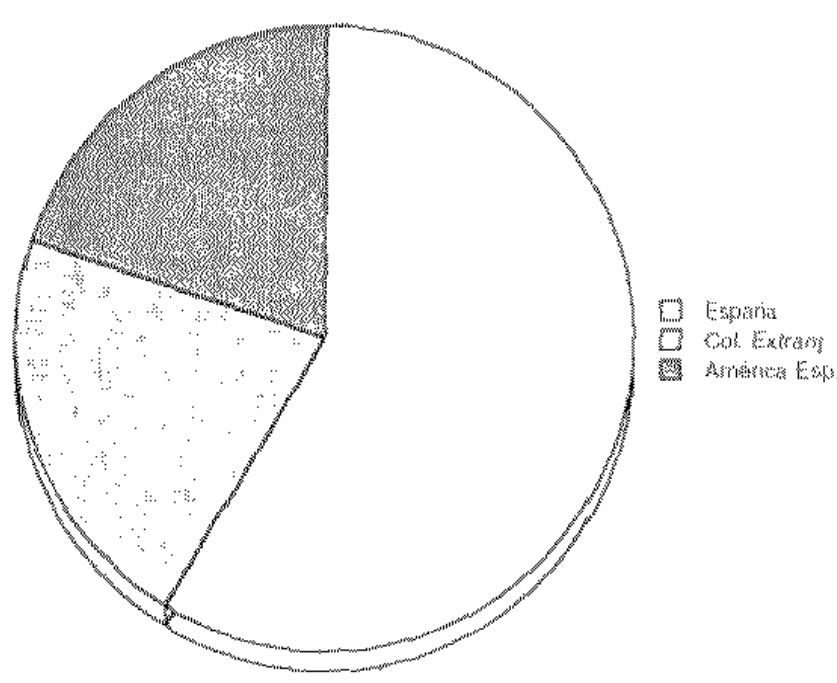


4.

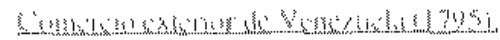

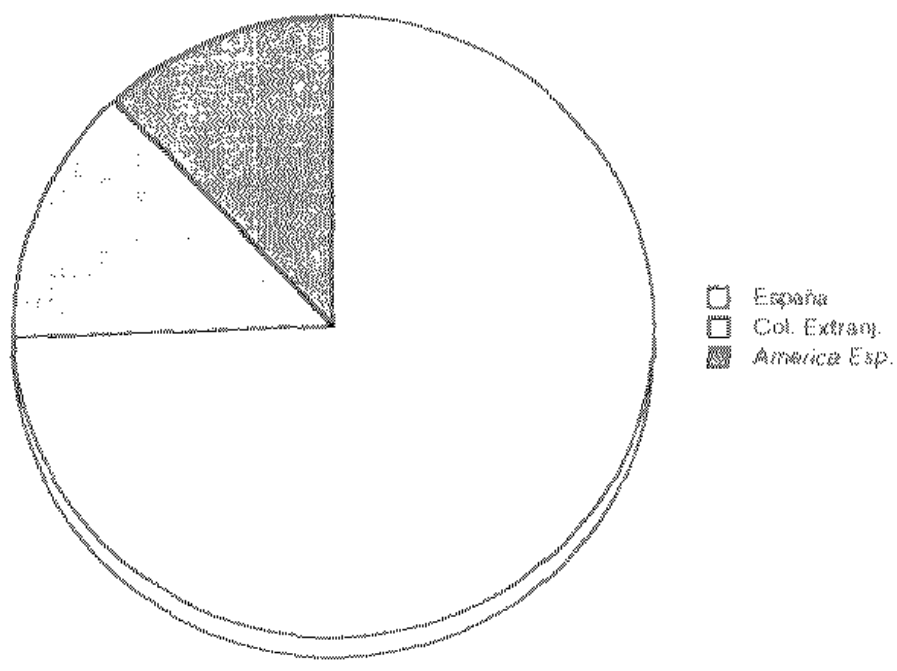

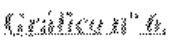

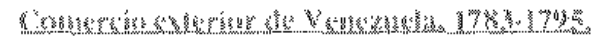

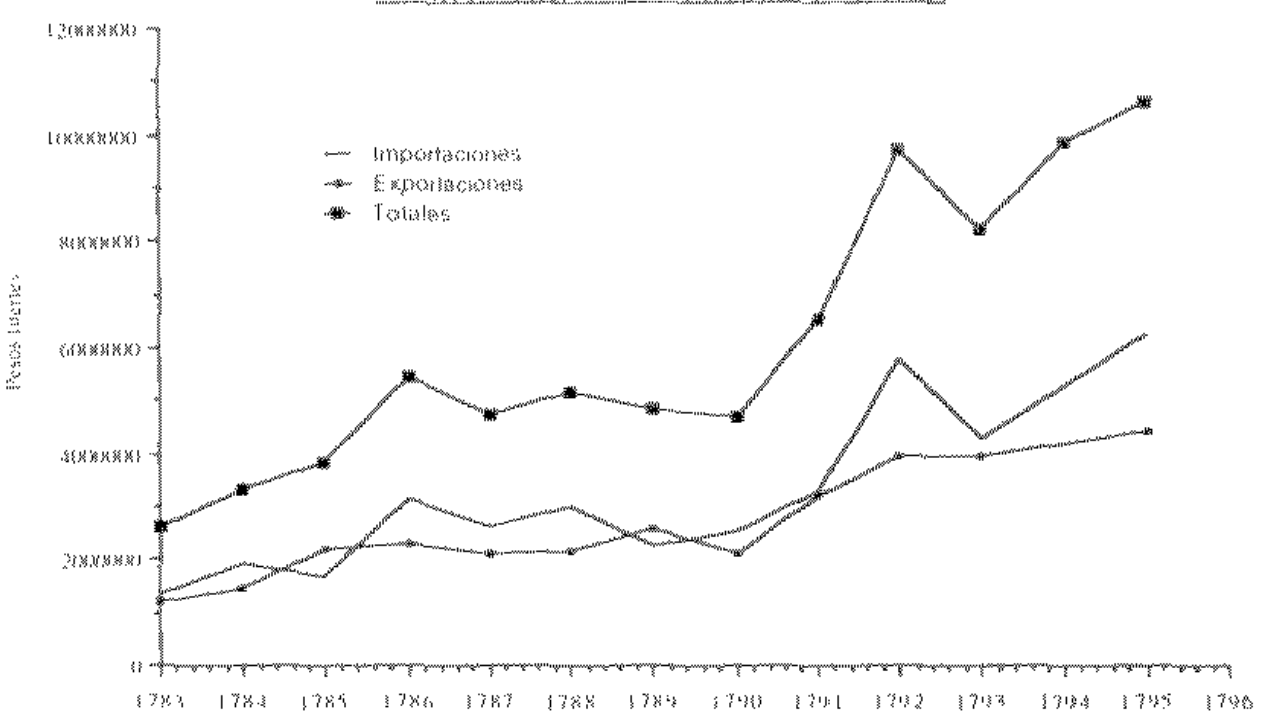


Gráfice " ?

Crecimiento percentual del comercio exterior de Venezuela.

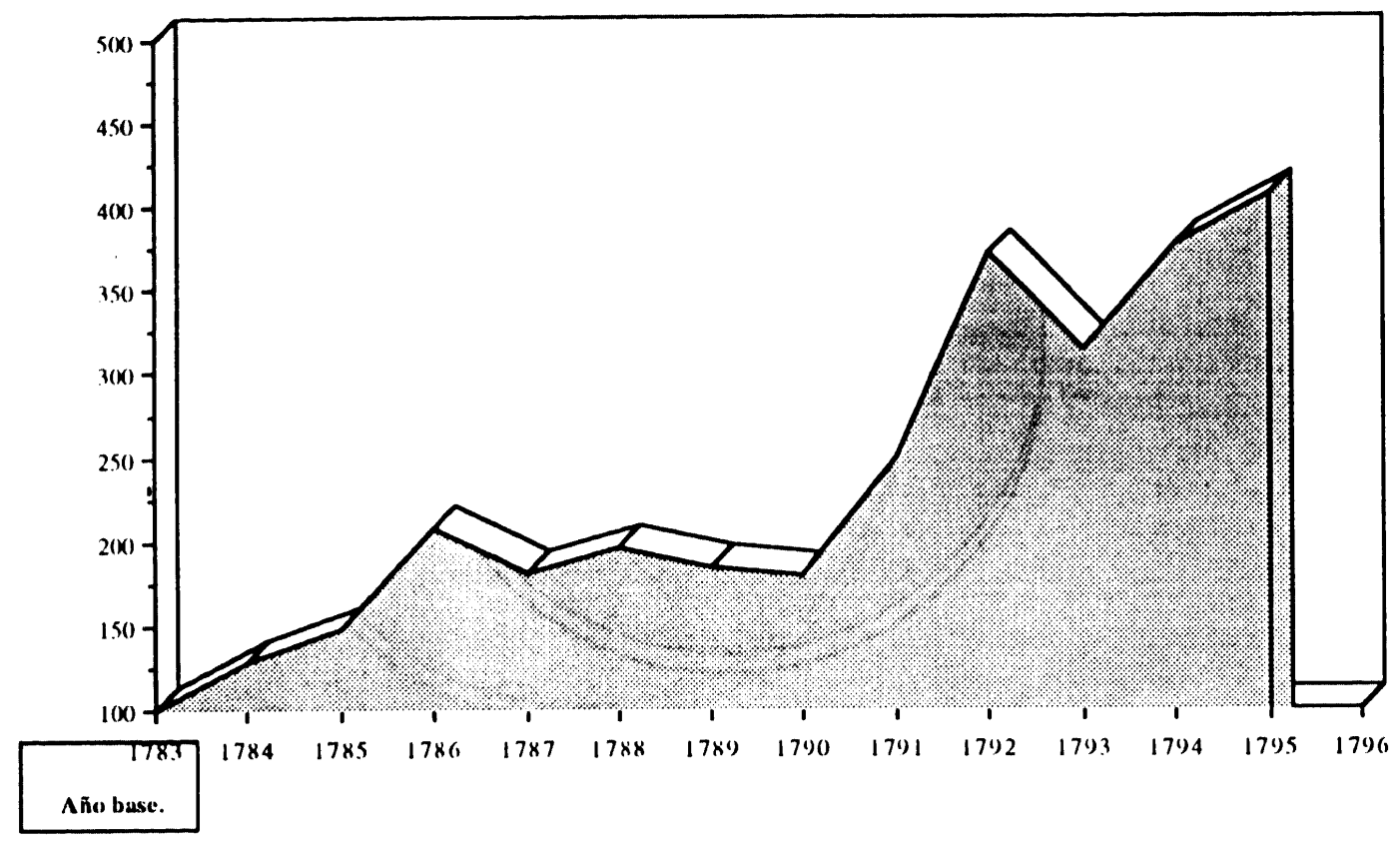

